Research Article

\title{
Theoretical and Experimental Study on the Antisliding Performance of Casting Steel Cable Clamps
}

\author{
Yangjie Ruan $\mathbb{D}^{1},{ }^{1,2}$ Bin Luo $\mathbb{D D}^{1,2}$ Mingmin Ding ${ }^{1},{ }^{3}$ Lifan Huang, ${ }^{1,2}$ and Zhengxing Guo ${ }^{1,2}$ \\ ${ }^{1}$ The Key Laboratory of C\&PC Structures of the Ministry of Education, Southeast University, Nanjing 210096, China \\ ${ }^{2}$ National Prestress Engineering Research Center, Southeast University, Nanjing 210096, China \\ ${ }^{3}$ College of Civil Engineering, Nanjing Forestry University, Nanjing 210037, China \\ Correspondence should be addressed to Bin Luo; seurobin@seu.edu.cn
}

Received 20 January 2019; Revised 30 March 2019; Accepted 10 April 2019; Published 2 May 2019

Academic Editor: Eric Lui

Copyright (C) 2019 Yangjie Ruan et al. This is an open access article distributed under the Creative Commons Attribution License, which permits unrestricted use, distribution, and reproduction in any medium, provided the original work is properly cited.

For large-span cable structures, a cable clamp is a key joint that connects adjacent structural components. In general, the antisliding performance of cable clamps determines their resistance capacity, and the antisliding force is generated by the clamping force induced by the high-strength bolts and the contact surfaces between the cable and the clamp. Since the existing methods are not sufficiently comprehensive for use to predict the precise bolt preload, a theoretical model developed by considering transversely isotropic material and the generalized Hook's law is presented to predict the attenuation values of the bolt clamping force and the corresponding parameters. Then, to meet the requirements of Eurocode 3, a new laboratory test is performed to reveal the antisliding mechanism of cable clamps, considering the effects of long-term creep and cable tension. According to the results of the data collected by real-time monitoring, the actual ultimate antisliding force of the clamp and the comprehensive friction coefficient are determined. Finally, a comparative study between the theoretical results and the experimental results is conducted. The proposed theoretical model can predict the actual attenuation of the bolt clamping force after cable tension. The results show that the stiffness of the clamp plate should be minimized when designing the clamp to reduce the loss of the bolt preload.

\section{Introduction}

In recent years, tensile structures have been widely used in various large-span projects, such as terminal buildings [1], Olympic stadiums [2], and astronomical telescopes [3]. A tensile structure is a type of prestressed structural system that utilizes cables and struts as its main forcebearing members; tensile structures include cable domes, suspended domes, and cable trusses $[4,5]$.

A cable clamp is a joint connecting adjacent cables and struts and has been adopted in the design of bridges and tensile structures. The function of the cable clamp makes it the key component in force transmission. In general, a nonsliding cable clamp consists of a main body, a steel plate, and several high-strength bolts. The highstrength bolts go through the upper main body and the bottom steel plate via the reserved bolt holes, holding the upper main body and steel plate together with preloads, so that the entire cable clamp has the structure of a compressive sandwich [6]. If the antisliding performance of the cable clamp is insufficient, the clamp will slide along the cable body, which may lead to the prestress loss of the entire structure and major safety hazards. Therefore, the antisliding performance of cable clamps is one of the key points in various stages of design, construction, and service. In actual projects, many engineering problems caused by insufficient antisliding resistance of the clamps may force the projects to be terminated or even rebuilt. For example, owing to their insufficient antisliding resistance at the bottom ends of the struts, the clamps of a beam-string structure, built in Shenzhen, China, slid along the cables, forced the struts to tilt, resulting in the extension of the construction deadline, as shown in Figure 1. Moreover, the tilted shape weakened the supporting capacity of the struts for the upper roof, leading to considerable potential safety hazards.

Furthermore, a suspension bridge built in Vietnam, as shown in Figure 2, encountered a similar problem during construction [7]. The clamps of the bridge are composed of two semicircular steel castings and several high-strengthbolts. 


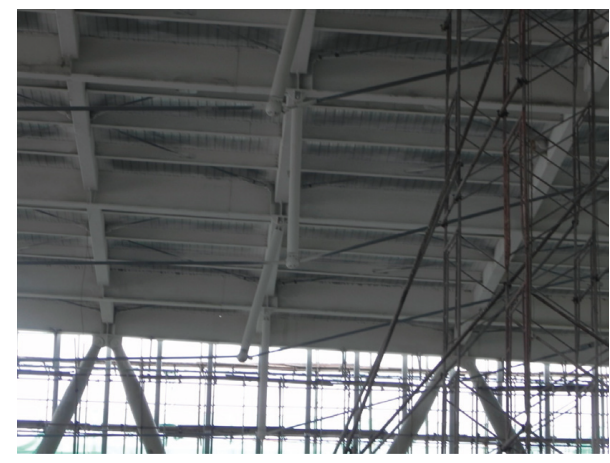

Figure 1: Cable clamp sliding along the cable of a beam-string structure.

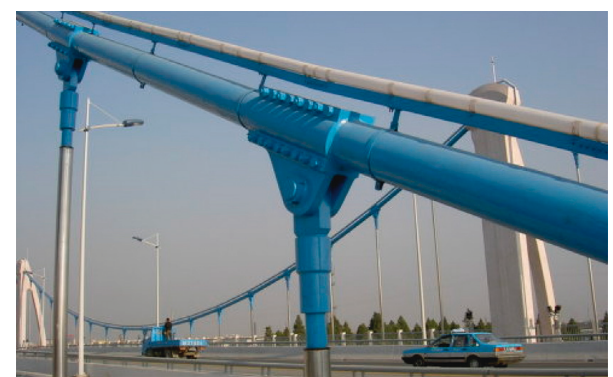

Figure 2: Cable clamp of a suspension bridge in Vietnam.

No slippage occurred during the installation of the cable clamps, but the cable clamp slid as the steel box girder was hoisted, forcing the project to stop until the cable clamp could be reinstalled. After analysis and discussion, it was determined that the insufficient pretightening force of the highstrength bolts and the overlarge drag force of the crane are the main reasons for the slippage of the cable clamp during construction.

In recent years, the antisliding performance of the cable clamp has been studied by several researchers through experimentation and numerical simulations. To prevent the slippage of these clamps, the requirements of antisliding performance have been included in many codes, such as Eurocode 3 (EN 1993-1-11:2006) [8], Structural Applications of Steel Cables for Buildings [9], and Specifications for Design of Highway Suspension Bridge (JTG/T D65-05-2015) [10]. As stated in Section 6.3.2, Eurocode 3 (EN 1993-1-11:2006) gives the detailed classical formula and the effects of the following parameters to determine the clamping force from preloaded bolts: (a) long-term creep; (b) reduction of diameter if tension is increased; (c) reduction of preload in clamp bolts by external forces. In general, the reduction in the preload of the bolts by external forces can be calculated by the axial forces and corresponding orientations of the structural components. In this case, it is necessary to determine the variation in the long-term creep and the reduction in the diameter after tension when determining the clamping force of the preloaded bolts. However, few studies on these aspects have been performed with comprehensive test methods or recommended parameter values.

The existing laboratory test studies of cable clamps mainly focus on safety verification. Zhao et al. [11] tested the antisliding performance of 4 groups of cable clamps used for the Hongdu Bridge in Nanchang, China, with a friction coefficient of 0.25 , which is larger than the value of 0.15 recommended by the Chinese specifications. Zhou et al. [12] found that the friction coefficient between casting steel clamps and cables made of zinc-aluminum alloy coated steel wires is 0.305 .

Furthermore, some numerical studies have been performed for comparison with laboratory tests. Luo et al. [13] carried out a full-scale model test of the cable clamp used in a cable dome structure. The static friction coefficient of the clamp was obtained and compared with the results of a finite element model analysis, and the improvement measures of adding stiffeners in the clamp groove to improve the antisliding performance of the clamp were put forward. CastroFresno et al. [14] described the design of a new metallic cable-joining clip for slope stabilization nets. The resistance capacity of new clip models with $\Phi 8 \mathrm{~mm}$ and $\Phi 10 \mathrm{~mm}$ was analyzed numerically and experimentally with ANSYS. The evaluation criteria of the antisliding failure of the clip and the parameter settings in the numerical simulation were proposed. The antisliding performance of semicircular clamps on bridge main cables, made of carbon fiber-reinforced polymer (CFRP), was studied by Zhuge et al. [15]. The coefficient between the CFRP wires and casting steel clamps was stable, while roughening the surface of the cable clamp could improve the antisliding performance of the cable clamp. Chen and Feng [16] conducted the nonlinear antisliding analysis of cable clamps by using ABAQUS, and the finite element model results were compared with the experimental results of the full-scale model. The antisliding capacity of the clamps was nonlinearly improved with increasing friction coefficient and bolt pretightening force.

Existing research has been conducted on the antisliding performance of cable clamps, and most of these papers lack an in-depth study of the tension in the cable, the variation in of the bolt clamping force, and the effect of the long-term creep. However, these aspects are clearly specified in Eurocode 3 (EN 1993-1-11:2006). Although complicated finite element numerical analyses have been carried out, no simple and convenient analytical formula has been proposed to predict the attenuation of the bolt clamping force.

Considering these aspects, this paper presents a modified theoretical model for calculating the attenuation of the bolts due to cable tension; this model is based on the transverse isotropic material theory [17] and generalized Hooke's law [18] and presented in the cylindrical coordinate system. This theoretical model is more convenient and faster to utilize than finite element analysis. Then, laboratory testing of four cables with different diameters cables is carried out to verify the theoretical model. Moreover, for the testing, a real-time monitoring system is introduced to reveal the antisliding mechanism of the cable clamps.

\section{Theoretical Model of the Reduction in Bolt Clamping Force}

The equation for calculating the ultimate antisliding force to prevent slipping of a cable clamp is provided in Section 6.4.1 in Eurocode 3 (EN 1993-1-11:2006) and is given by 


$$
F_{\mathrm{Ed}} \leq \frac{\left(F_{\mathrm{Ed}_{\perp}}+F_{\mathrm{r}}\right) \mu}{\gamma_{\mathrm{M}, \mathrm{fr}}},
$$

where $F_{\mathrm{Ed}}$ is the component of the external design load parallel to the cable, $F_{\mathrm{Ed}}$ is the component of the external design load perpendicular to the cable, $F_{\mathrm{r}}$ is the radial clamping force considered that may be reduced, $\mu$ is the coefficient of friction, and $\gamma_{\mathrm{M} \text {,fr }}$ is the partial factor for friction and recommended to be 1.65 .

In equation (1), the external force, $F_{\mathrm{Ed}_{\perp}}$, can be obtained by the design information, and the friction coefficient, $\mu$, can be determined in the test. In this case, the bolt clamping force, $F_{\mathrm{r}}$, is a key factor that cannot be directly obtained. However, $F_{\mathrm{r}}$ is a changing parameter, mainly caused by the reduction in cable diameter and the effect of long-term creep, and no recommended values are given in the code.

2.1. Theoretical Model Establishment. The antisliding performance of the cable clamp is a typical solid friction problem. The surface of the cable clamp groove and the surface of the cable body constitute a friction pair. The classical friction law is used to calculate the ultimate antisliding force without considering the reduction in cable diameter. Assuming that the cable clamp groove is in full contact with the cable body, the radial pressure generated by the cable clamp is uniformly distributed along the circumference of the cable. The sum of the clamping force of all the high-strength bolts, $P_{\text {tot }}$, is equivalent to the sum of the pressure stresses acting on the clamp groove and is given in equation (2). Figure 3 shows the antisliding mechanics of a cable clamp.

$$
P_{\text {tot }}=\int_{0}^{\pi} p l R \sin \theta d \theta=2 p l R,
$$

where $l$ is the length of the clamp groove, $R$ is the diameter of the cable cross section, and $p$ is the pressure stress on the clamp groove. Therefore, the ultimate antisliding force $F_{\mathrm{fc}}$ can be obtained by

$$
F_{\mathrm{fc}}=\mu P_{\mathrm{tot}}=2 \mu p l R .
$$

The relationship between the bolt clamping force, cable tension, cable cross-sectional diameter, and bolt length is shown in Figure 4. As the bolts are preloaded and stabilized, the cable diameter will decrease. Then, the cable is tensioned, and the cable diameter is clearly reduced again. This change will lead to a reduction in the bolt length; thus, the clamping force of the bolts will be reduced. The cable diameter will be increased due to the reduction in the bolt clamping force.

First, the cylindrical coordinate system is established, as shown in Figure 5(a), where $z$ is the axial direction of the cable and $r$ and $\theta$ are the polar coordinates of the section plane of the cable. To determine the influence of the reduction in the cable diameter on the bolt clamping force, the cables were simplified as transversely isotropic materials. Transversely isotropic materials have uniform elastic properties in all directions in a certain plane but different elastic properties perpendicular to this plane, similar to the properties of the fiber-reinforced model shown in Figure 5(b), where $E_{z z}$ is the axial elastic modulus of the cable, $E_{r r}$ is the radial elastic modulus, $E_{\theta \theta}$ is the circumferential elastic modulus, $v_{r z}$ is the radial to axial Poisson's ratio of the cable, $v_{r \theta}$ is the radial to circumferential Poisson's ratio of the cable, $D$ is the diameter of the cable, $P_{\mathrm{T}}$ is the clamping force of a single high-strength bolt, $l_{\mathrm{a}}$ is the groove length of the cable clamp, $l_{\mathrm{b}}$ is the net length of the high-strength bolt (the length between the upper surface and lower surface of the whole cable clamp), $E_{\mathrm{b}}$ is the elastic modulus of the high-strength bolts, $m$ is the number of bolts used in the clamp, and $\Delta F$ is the cable tension force increment after preloading the bolts. Assuming that the cable clamp is a rigid body, no deformation occurs under the bolt clamping force.

Typical cables are made of spiraled steel wires, so voids must exist between the wires, as shown in Figure 6. In other words, the sum of the metallic cross-sectional area, $A_{s}$, is smaller than the global cross-sectional area of the cable, $A_{\mathrm{g}}$. In the theoretical model, the cross section of a cable is simplified as a uniform and solid circular cross section, which is equal to $A_{\mathrm{g}}$, ignoring the voids. To maintain that, the stiffness in the axial direction, $E_{z z} A$, is constant and the equivalent elastic modulus of the cable in the theoretical model, $E_{e, z z}$, is introduced in equation (4). $E_{e, r r}$ and $E_{e, \theta \theta}$ are also multiplied by $\varphi_{e}$ to reduce the elastic modulus.

$$
E_{e, z z}=\frac{E_{z z} A_{s}}{A_{\mathrm{g}}}=\frac{4 E_{z z} A_{s}}{\pi D^{2}}=\varphi_{e} E_{z z},
$$

where $E_{e, z z}, E_{e, r r}$, and $E_{e, \theta \theta}$ are the equivalent elastic moduli in the three directions, respectively; $A_{\mathrm{g}}$ is the global cable cross-sectional area $A_{\mathrm{g}}=\left(\pi D^{2}\right) / 4 ; A_{\mathrm{s}}$ is the sum of the metallic cross-sectional area of the wires in the cable; and $\varphi_{e}$ is the reduction factor of the elastic modulus $\varphi_{e}=\left(4 A_{s}\right) / \pi D^{2}$.

According to the assumptions above, the pressure on the surface of a cable distributes uniformly, so the following relationship can be obtained:

$$
\left\{\begin{array}{l}
\sigma_{z r}=\sigma_{r \theta}=\sigma_{z \theta} \\
\varepsilon_{z r}=\varepsilon_{r \theta}=\varepsilon_{z \theta}
\end{array}\right.
$$

According to generalized Hooke's law, the strain of the cable in the three directions of the cylindrical coordinate system can be expressed as

$$
\left\{\begin{array}{l}
\varepsilon_{z z}=\frac{\sigma_{z z}}{E_{e, z z}}-v_{z \theta} \frac{\sigma_{\theta \theta}}{E_{e, \theta \theta}}-v_{z r} \frac{\sigma_{r r}}{E_{e, r r}}, \\
\varepsilon_{r r}=\frac{\sigma_{r r}}{E_{e, r r}}-v_{r z} \frac{\sigma_{z z}}{E_{e, z z}}-v_{r \theta} \frac{\sigma_{\theta \theta}}{E_{e, \theta \theta}}, \\
\varepsilon_{\theta \theta}=\frac{\sigma_{\theta \theta}}{E_{e, \theta \theta}}-v_{\theta z} \frac{\sigma_{z z}}{E_{e, z z}}-v_{\theta r} \frac{\sigma_{r r}}{E_{e, r r}},
\end{array}\right.
$$

where $\varepsilon_{z z}, \varepsilon_{r r}$, and $\varepsilon_{\theta \theta}$ are the strains in the cylindrical coordinate system; $\sigma_{z z}, \sigma_{\theta \theta}$, and $\sigma_{r r}$ are the corresponding stresses; $E_{e, z z}, E_{e, r r}$, and $E_{e, \theta \theta}$ are the equivalent elastic moduli in the three directions; and $v_{x x}$ is the corresponding Poisson's ratio of the cable. 



Figure 3: Schematic diagram of the antisliding mechanics of a cable clamp.

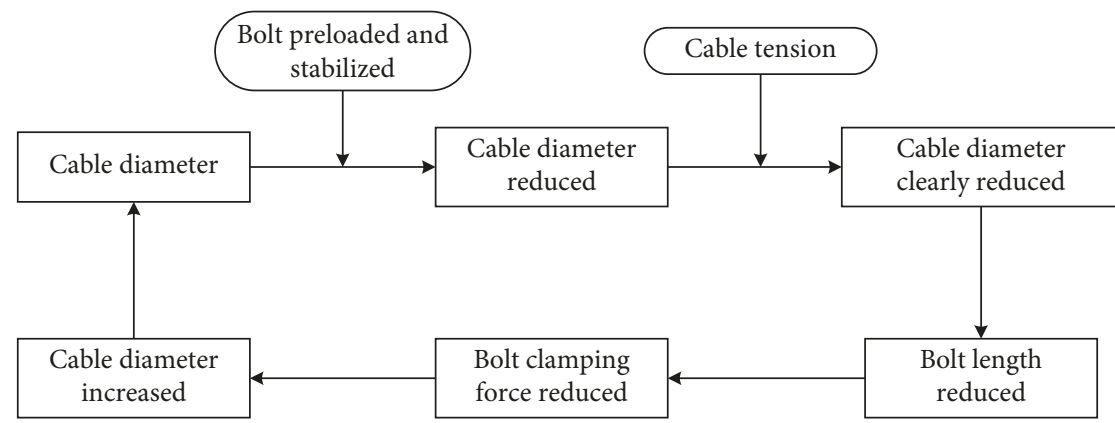

Figure 4: Relationship of bolt clamping force, cable tension, cable cross-sectional diameter, and bolt length.



(a)

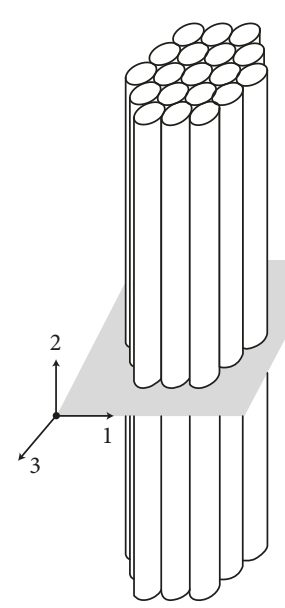

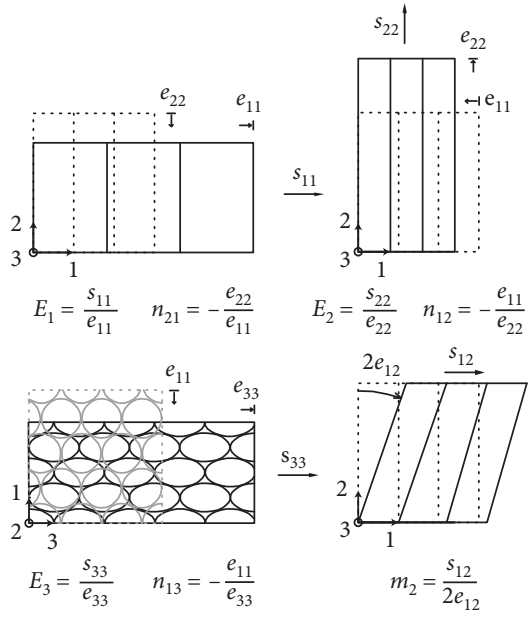

(b)

FIgURE 5: Simplified cable model. (a) Cylindrical coordinate system. (b) Fiber-reinforced model.
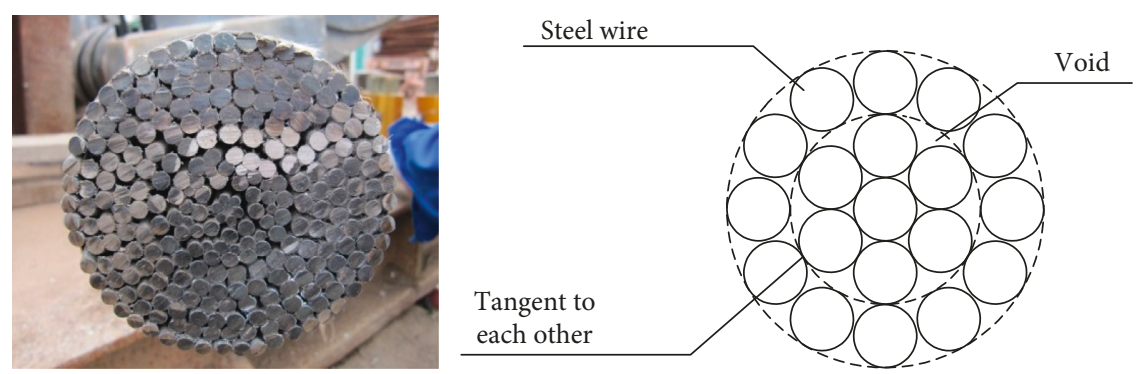

FIgURE 6: Cross section of a spiral strand. 
According to the characteristics of transversely isotropic material, the variation in the stress in the cable crosssectional plane is uniform and can be expressed as

$$
\Delta p=\Delta \sigma_{r r}=\frac{\Delta P_{\text {tot }}}{D l_{\mathrm{a}}}=\frac{m \Delta P_{\mathrm{T}}}{D l_{\mathrm{a}}},
$$

where $\Delta p$ is the variation in the pressure stress on the clamp groove due to the change in cable tension and $\Delta P_{\mathrm{T}}$ is the variation in a single bolt clamping force caused by the cable tension force increment.

According to equations (6) and (7), the variation in the radial strain of the cable can be obtained as follows:

$$
\begin{aligned}
\Delta \varepsilon_{r r} & =\frac{\Delta p}{E_{e, r r}}-v_{r z} \frac{\Delta \sigma_{z z}}{E_{e, z z}}-v_{r \theta} \frac{\Delta p}{E_{e, \theta \theta}} \\
& =\left(\frac{1}{E_{e, r r}}-\frac{v_{r \theta}}{E_{e, \theta \theta}}\right) \cdot \Delta p-v_{r z} \frac{\Delta \sigma_{z z}}{E_{e, z z}} .
\end{aligned}
$$

Because $\Delta \sigma_{z z}$ is the axial stress of the cable and the cable tension force increment is $\Delta F$, the diameter of the cable section is $D$, so $\Delta \sigma_{z z}=(4 \Delta F) / \pi D^{2}$.

Assuming that the variation in length of a single bolt is $\Delta_{l_{\mathrm{b}}}$ and that the variation in the diameter of the cable section is $\Delta_{D}, \Delta_{l_{b}}$ can be obtained by equation (9) according to the net length of the high-strength bolt, and $\Delta_{l_{\mathrm{b}}}$ is a variable value related to the cable tension force increment $\Delta F$.

$$
\Delta_{l_{\mathrm{b}}}=\Delta \varepsilon_{\mathrm{b}} \cdot l_{\mathrm{b}}=\frac{\Delta \sigma_{\mathrm{b}}}{E_{\mathrm{b}}} \cdot l_{\mathrm{b}}=\frac{-\Delta P_{\mathrm{T}}}{E_{\mathrm{b}} \cdot\left(\left(\pi d^{2}\right) / 4\right)} \cdot l_{\mathrm{b}}=-\frac{4 \Delta P_{\mathrm{T}} l_{\mathrm{b}}}{E_{\mathrm{b}} \pi d^{2}} .
$$

With the tensioning of the cable, the cable diameter clearly reduces, and the bolt clamping force reduces. Therefore, the variation in the cable diameter, $\Delta_{c}$, is related to the cable force increment, $\Delta F$, and the variation in the bolt clamping force, $\Delta P_{\mathrm{T}}$. According to the variation in the radial strain of the cable section, $\varepsilon_{r r}$, described in equation (8) and the diameter of the cable, $D, \Delta_{c}$ can be obtained as follows:

$$
\begin{aligned}
\Delta_{\mathrm{c}} & =\Delta \varepsilon_{r r} \cdot D \\
& =\left[\left(\frac{1}{E_{e, r r}}-\frac{v_{r \theta}}{E_{e, \theta \theta}}\right) \cdot \Delta p-v_{r z} \frac{\Delta \sigma_{z z}}{E_{e, z z}}\right] \cdot D \\
& =\left[\left(\frac{1}{E_{e, r r}}-\frac{v_{r \theta}}{E_{e, \theta \theta}}\right) \cdot \frac{m \Delta P_{\mathrm{T}}}{2 R l_{\mathrm{a}}}-\frac{\nu_{r z}}{E_{e, z z}} \cdot \frac{\Delta F}{\pi R^{2}}\right] \cdot D \\
& =\left(\frac{1}{E_{e, r r}}-\frac{v_{r \theta}}{E_{e, \theta \theta}}\right) \cdot \frac{m \Delta P_{\mathrm{T}}}{l_{\mathrm{a}}}-\frac{4 v_{r z} \Delta F}{E_{e, z z} \pi D} .
\end{aligned}
$$

Because the cable clamp and the cable body are closely attached together by high-strength bolts, the deformation coordination condition (equation (11)) should be satisfied:

$$
\Delta_{\mathrm{b}}=\Delta_{\mathrm{c}}
$$

According to equations (9)-(11), the variation in a single bolt clamping force, $\Delta P_{\mathrm{T}}$, is derived as follows:

$$
\begin{aligned}
\Delta P_{\mathrm{T}} & =\frac{4 v_{r z} \Delta F}{\pi D E_{e, z z} \cdot\left[\left(m / l_{\mathrm{a}}\right)\left(\left(1 / E_{e, r r}\right)-\left(v_{r \theta} / E_{e, \theta \theta}\right)\right)+\left(\left(4 l_{\mathrm{b}}\right) / E_{\mathrm{b}} \pi d^{2}\right)\right]} \\
& =\frac{4 v_{r z} \Delta F l_{\mathrm{a}} d^{2} E_{\mathrm{b}} E_{r r} E_{\theta \theta}}{D E_{z z}\left[\pi m d^{2} E_{\mathrm{b}}\left(E_{\theta \theta}-v_{r \theta} E_{r r}\right)+4 \varphi_{e} l_{\mathrm{a}} l_{\mathrm{b}} E_{r r} E_{\theta \theta}\right]} .
\end{aligned}
$$

Therefore, the sum of the variation in the bolt clamping force should be $m \Delta P_{\mathrm{T}}$. In equation (12), $m d^{2}$ can be obtained as

$$
m d^{2}=\frac{4 A_{\mathrm{sum}, \mathrm{b}}}{\pi}
$$

where $A_{\text {sum,b }}$ is the total cross-sectional area of $m$ bolts. Therefore, the sum of the variation in bolt clamping force can be obtained by

$$
\begin{aligned}
\sum_{i=1}^{m} \Delta P_{\mathrm{T}, i} & =m \Delta P_{\mathrm{T}} \\
& =\frac{4 v_{r z} \Delta F l_{\mathrm{a}} m d^{2} E_{\mathrm{b}} E_{r r} E_{\theta \theta}}{D E_{z z}\left[\pi m d^{2} E_{\mathrm{b}}\left(E_{\theta \theta}-v_{r \theta} E_{r r}\right)+4 \varphi_{e} l_{\mathrm{a}} l_{\mathrm{b}} E_{r r} E_{\theta \theta}\right]} \\
& =\frac{4 v_{r z} \Delta F l_{\mathrm{a}} E_{\mathrm{b}} E_{r r} E_{\theta \theta}}{D E_{z z}\left[\pi E_{\mathrm{b}}\left(E_{\theta \theta}-v_{r \theta} E_{r r}\right)+\left(\left(4 \varphi_{e} l_{\mathrm{a}} l_{\mathrm{b}} E_{r r} E_{\theta \theta}\right) / m d^{2}\right)\right]} \\
& =\frac{4 v_{r z} \Delta F l_{\mathrm{a}} E_{\mathrm{b}} E_{r r} E_{\theta \theta}}{D E_{z z}\left[\pi E_{\mathrm{b}}\left(E_{\theta \theta}-v_{r \theta} E_{r r}\right)+\left(\left(\pi \varphi_{e} l_{\mathrm{a}} l_{\mathrm{b}} E_{r r} E_{\theta \theta}\right) / A_{\mathrm{sum}, \mathrm{b}}\right)\right]} .
\end{aligned}
$$

When a cable tension force of $\Delta F$ is applied to the cable, the sum of the variations in the clamping force of all the high-strength bolts should be $\sum_{i=1}^{m} \Delta P_{\mathrm{T}, i}$, and the sum of the bolt clamping force should be adjusted to the following equation:

$$
\begin{aligned}
P_{\text {tot }} & =m P_{\mathrm{T}}-\sum_{i=1}^{m} \Delta P_{\mathrm{T}, i} \\
& =m P_{\mathrm{T}}-\frac{4 v_{r z} \Delta F l_{\mathrm{a}} E_{\mathrm{b}} E_{r r} E_{\theta \theta}}{D E_{z z}\left[\pi E_{\mathrm{b}}\left(E_{\theta \theta}-v_{r \theta} E_{r r}\right)+\left(\left(\pi \varphi_{e} l_{\mathrm{a}} l_{\mathrm{b}} E_{r r} E_{\theta \theta}\right) / A_{\text {sum }, \mathrm{b}}\right)\right]} .
\end{aligned}
$$

The cross section of the cable in Figure 6 shows that a cable is made by twisting several circular steel wires, and the circular steel wires are tangent to each other [19]. Therefore, when the cable is tensioned, tangential deformation between the wires easily occurs, so the radial to circumferential Poisson's ratio $v_{r \theta}$ should be approximately 0 .

2.2. Parametric Analysis. To explore the influence of certain parameters on the variation in bolt clamping force, a parametric analysis is performed. First, a group of default properties for a clamp-cable assembly is set, as listed in Table 1.

Then, one parameter among $\Delta F, l_{\mathrm{a}}, l_{\mathrm{b}}, D$, and $A_{\text {sum, }}$ is changed, while the values of the other parameters remain unchanged. The sum of the variation in the bolt clamping force $\sum_{i=1}^{m} \Delta P_{\mathrm{T}, i}$ is calculated by equation (14), and the results 
TABLe 1: Default properties of the clamp-cable assembly.

\begin{tabular}{|c|c|c|c|}
\hline \multicolumn{2}{|l|}{ Properties of the clamp-cable assembly } & \multicolumn{2}{|l|}{ Material properties } \\
\hline Cable tension force increment, $\Delta F(\mathrm{kN})$ & 6000 & Poisson's ratio, $v_{r z}$ & 0.3 \\
\hline Groove length of the cable clamp, $l_{\mathrm{a}}(\mathrm{mm})$ & 400 & Poisson's ratio, $v_{r \theta}$ & 0 \\
\hline Net length of the high-strength bolt, $l_{\mathrm{b}}(\mathrm{mm})$ & 300 & Axial elastic modulus of the cable, $E_{z z}(\mathrm{MPa})$ & 160000 \\
\hline Diameter of the cable, $D(\mathrm{~mm})$ & 100 & Radial elastic modulus of the cable, $E_{r r}(\mathrm{MPa})$ & 206000 \\
\hline Diameter of the high-strength bolt, $d$ ( $\mathrm{mm}$ ) & 20 & Circumferential elastic modulus of the cable, $E_{\theta \theta}(\mathrm{MPa})$ & 206000 \\
\hline Number of bolts, $m$ & 8 & Elastic modulus of the high-strength bolt, $E_{\mathrm{b}}(\mathrm{MPa})$ & 206000 \\
\hline Total cross-sectional area of the $m$ bolts, $A_{\text {sum,b }}$ & $800 \pi$ & Reduction factor of the elastic modulus, $\varphi_{e}$ & 0.75 \\
\hline
\end{tabular}

are shown in Figure 7. The sum of the variation in bolt clamping force linearly increases with the cable tension force increment, $\Delta F$. The groove length of the cable clamp, $l_{\mathrm{a}}$, has a small influence on $\sum_{i=1}^{m} \Delta P_{\mathrm{T}, i}$, and $\sum_{i=1}^{m} \Delta P_{\mathrm{T}, i}$ tends to remain constant as $l_{\mathrm{a}}$ increases. $\sum_{i=1}^{m} \Delta P_{\mathrm{T}, i}$ decreases significantly and nonlinearly with increasing bolt net length, $l_{\mathrm{b}}$, and cable diameter, $D \sum_{i=1}^{m} \Delta P_{\mathrm{T}, i}$, increases significantly and almost linearly with the increase in the total cross-sectional area of all the bolts, $A_{\text {sum,b }}$.

\section{Experimental Study on Cable Clamp}

3.1. Test Method. Most existing experimental studies on cable clamps ignore the effect of cable tension; therefore, the actual state of the cables in a real project cannot be reflected. Thus, the acquisition of the test data is inadequate when the clamping force of high-strength bolts is not monitored in real time.

In this paper, testing of the antisliding performance of cable clamp is carried out with specimens at a 1:1 scale. The design of this cable clamp test system is shown in Figure 8. According to the requirements stated in Section 6.3.2 of Eurocode 3 (EN 1993-1-11:2006), the reduction in the cable section diameter after the cable stretched and creeped is taken into account. The cables are installed in the tensioning machine and stretched to the designed tension force of the service state. Then, a real-time data acquisition system measures the clamping force of the high-strength bolts, the sliding displacement of the clamp, and the pushing force on the clamp. The pushing test is performed when the bolt clamping force is stabilized.

The difference of the cable force is derived from the component force generated by the connecting member of the cable clamp in the direction of the cable. In common cases, the cable clamp is generally composed of a main body and clamp plate. The function of the main body is connecting the components (e.g., strut and other cable) to the clamp and bearing structural loads directly. However, the clamp plate does not connect with any component of the structure except the cable. The function of the clamp plate is simply to clamp the cable and balance the friction force. Therefore, the friction force provided by the clamp plate is not affected by external forces in other directions, as shown in Figure 9. In the laboratory test, to simulate the actual situation, the pushing force of the hydraulic jacks is applied to only the main body of the clamp.

The detailed procedure of the antisliding test is listed as follows:
(1) Install the cable on the tensioning machine, install the cable clamp specimen and bolt pressure sensors on the corresponding cable, and screw in the highstrength bolts to achieve the designed preload with the tightening sequence shown in Figure 10.

(2) Stand up the clamp-cable assembly, and monitor the reduction in the clamping force of the high-strength bolts in real time, until the bolt clamping force is stable, during which time the cable is in a nonstress state.

(3) Gradually tension the cable to the designed cable force, and simultaneously observe the reduction in bolt clamping force.

(4) Maintain the designed cable force by the tension machine, and simultaneously monitor the bolt clamping force until stable.

(5) Place the double parallel hydraulic jacks on both sides of the cable body between the test cable clamp and the reaction frame, and set the pushing force sensors between the jacks and the test clamp.

(6) Operate the double parallel hydraulic jacks synchronously, and push the main body of the test clamp incrementally. The load is added to the main body (plate A) of the clamp, following Figure 11. The Jack pushing force, the bolt clamping force, and the sliding displacement of the test cable clamp data are collected in real time.

(7) Stop pushing the clamp when the slippage of the cable clamp begins to rapidly increase.

(8) Process the test data, determine the ultimate antisliding force of the cable clamp by drawing the forceslippage curve, and calculate the friction coefficient between the cable body and the clamp based on the final clamping force of the bolts obtained from the pressure sensors.

3.2. Specimen Design. In this paper, the specimens are the cable clamps used for the Zhengzhou Olympic Sports Center in China, a large stadium that can accommodate more than 60,000 people. The prestressed cable system is a cablesupported grid with a span of $311.6 \mathrm{~m}$. Galfan cables with four different diameters that meet the requirements of $\mathrm{GB} / \mathrm{T}$ 20492-2006 [20] are used in this project. The casting steel cable clamp, as shown in Figure 11, is manufactured according to JGJ/T 395-2017 [21]. The material grade of the cable clamp is G20Mn5QT. The ends of the clamp groove are 


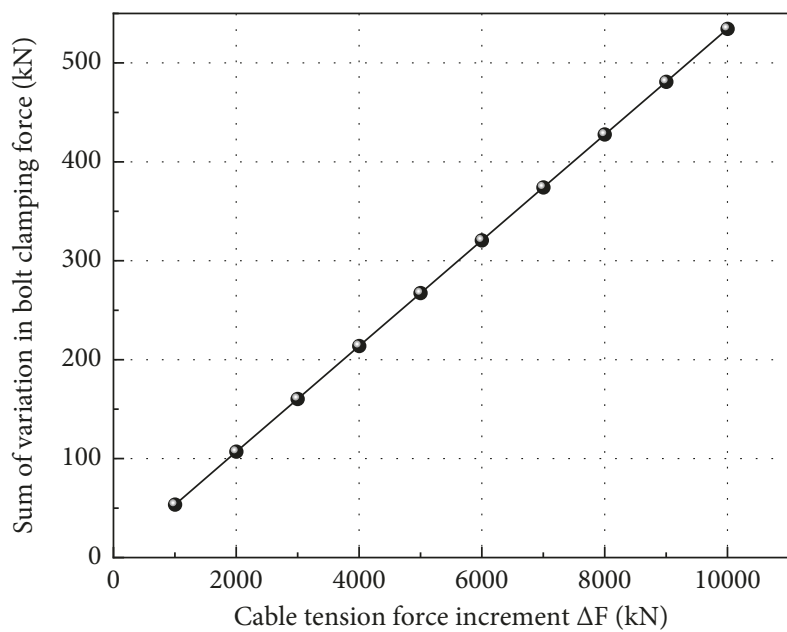

(a)

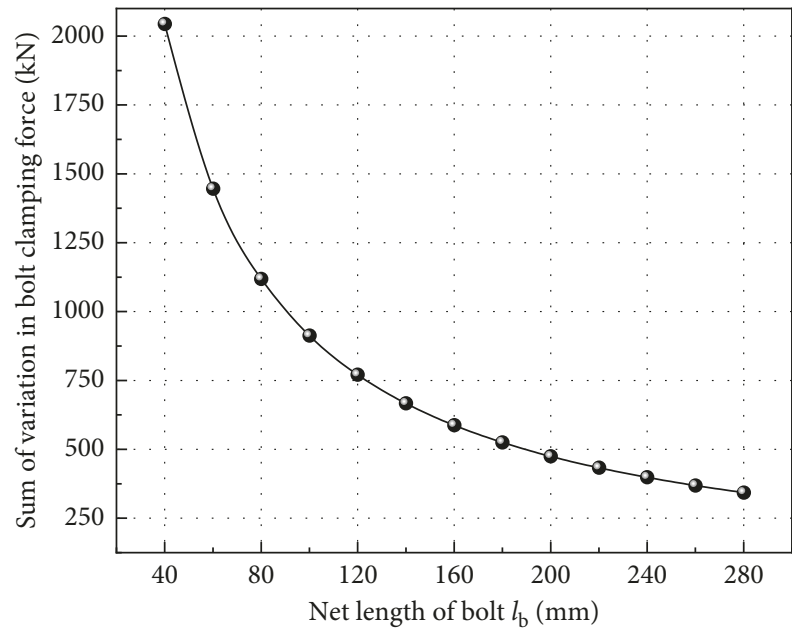

(c)

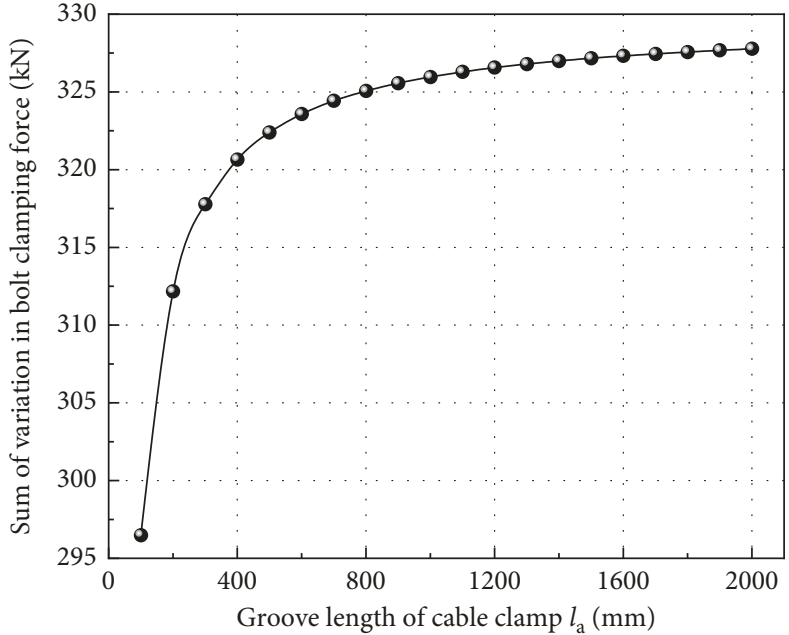

(b)

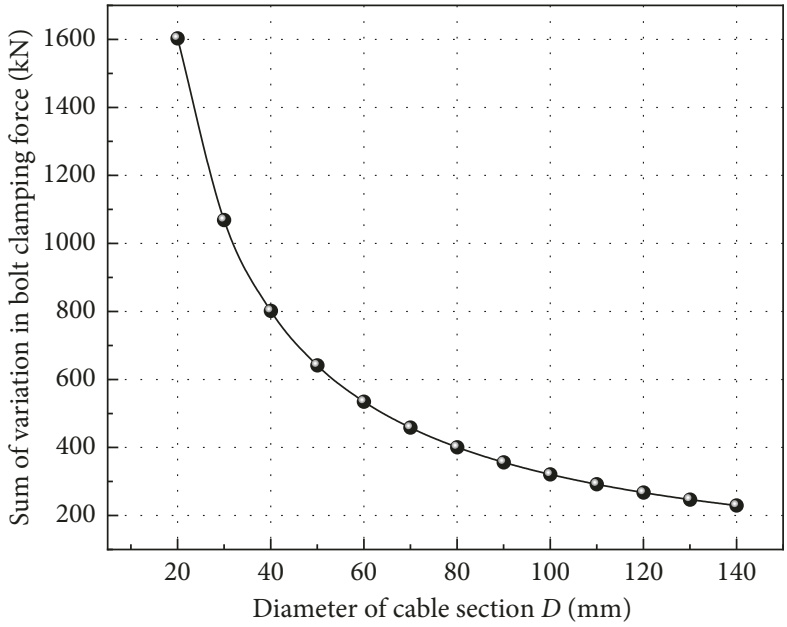

(d)

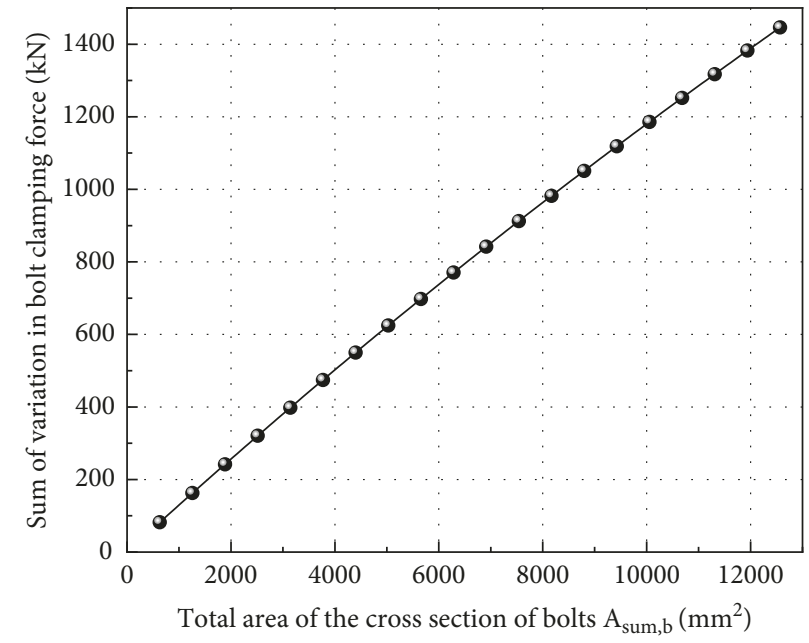

(e)

FIgURE 7: Influence of the parameters on the variation in bolt clamping force for the theoretical model. (a) $\Delta F$ vs. $\sum_{i=1}^{m} \Delta P_{\mathrm{T}, i}$ curve; (b) $l_{\mathrm{a}}$ vs. $\sum_{i=1}^{m} \Delta P_{\mathrm{T}, i}$ curve; (c) $l_{\mathrm{b}}$ vs. $\sum_{i=1}^{m} \Delta P_{\mathrm{T}, i}$ curve; (d) $D$ vs. $\sum_{i=1}^{m} \Delta P_{\mathrm{T}, i}$ curve; (e) $A_{\text {sum }, \mathrm{b}}$ vs. $\sum_{i=1}^{m} \Delta P_{\mathrm{T}, i}$ curve. 


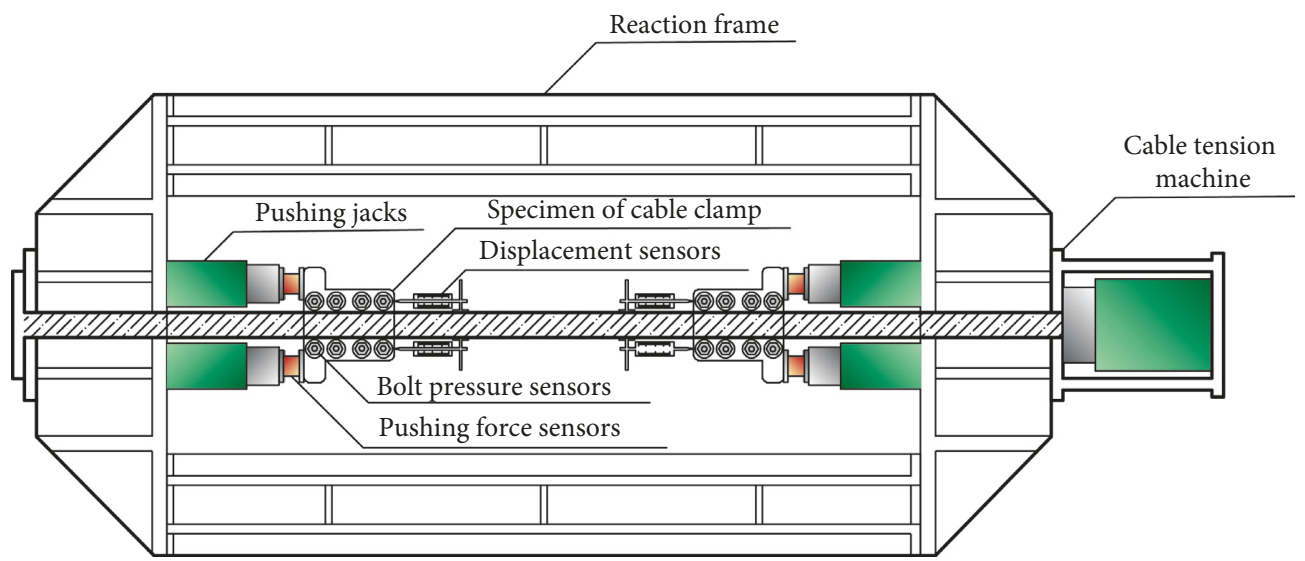

FIGURE 8: Real-time monitoring test system for cable clamps.

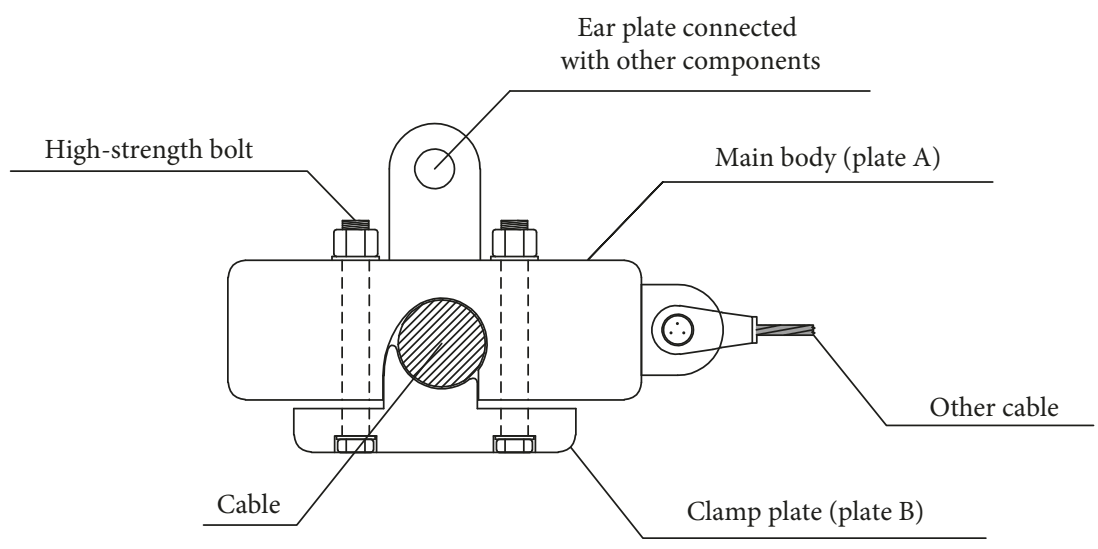

Figure 9: The composition of a cable clamp.

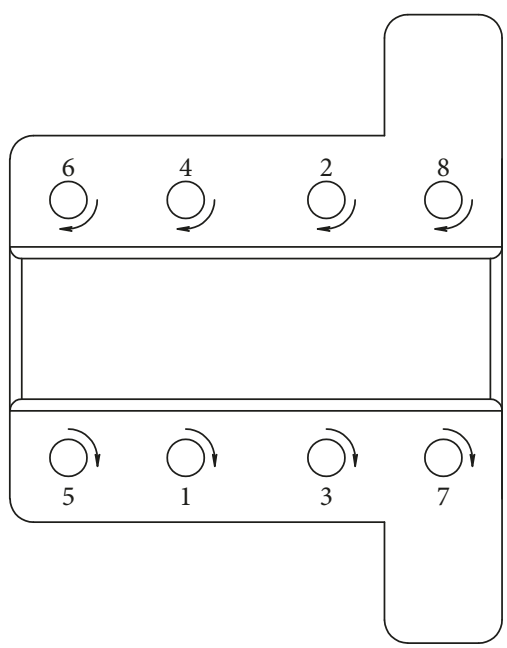

FIGURE 10: Tightening sequence of the high-strength bolts.

rounded to a radius greater than $20 \mathrm{~mm}$, and the grooves are cut by fine machining to meet the accuracy requirement. The groove surfaces, which are in contact with the cable body, are treated by applying a zinc coating with a thickness of $1 \mathrm{~mm}$ using thermal spray technology to protect the cable body and to meet the requirements stated in Section 4.5 of Eurocode 3 (EN 1993-1-11:2006). The bolts are friction type 8.8s grade
M27 high-strength bolts with a large hexagon head and meet the requirements of GB/T 1231-2006 [22]. The details of the specimens are listed in Tables 2 and 3.

The laboratory testing system of the clamp-cable assembly is shown in Figure 12. Two cable clamps were installed on the same cable, which was unused before testing. As the bolts are M27-8.8s, the bolts should be screwed to $232 \mathrm{kN}$ (i.e., the preload) by electric torque wrench. Each bolt has a pressure sensor attached to it. Then, the system will be monitored in the standing state until the attenuation of the bolt clamping force becomes stable. The cables are tensioned to the design loads in 10 steps to observe the change in the bolt clamping force. Next, the clamp is pushed parallel to the cable until it slips. Throughout this process, the bolt clamping force, the pushing force on the clamp, and the sliding displacement of the clamp are monitored in real time and by the same system.

\subsection{Test Results and Discussion}

3.3.1. Failure Modes of the Clamp-Cable Assemblies. The cable was unloaded, the cable clamp was opened, and the changes in the cable and the clamp after the antisliding failure of the cable clamps occurs were observe. Obvious scratches are apparent on the surface of the cable body. The surface of 


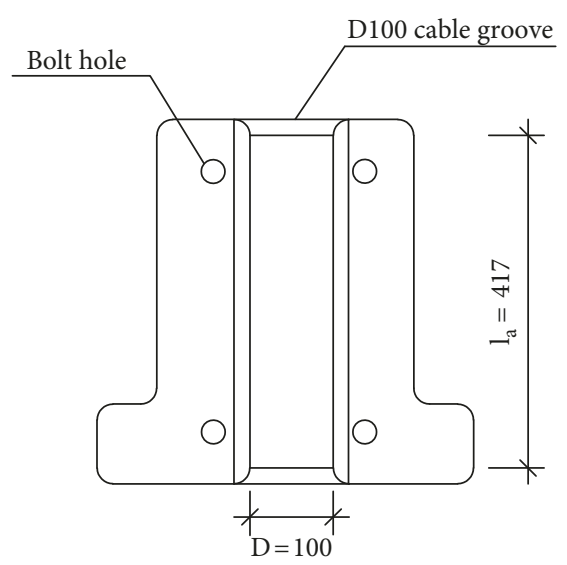

(a)

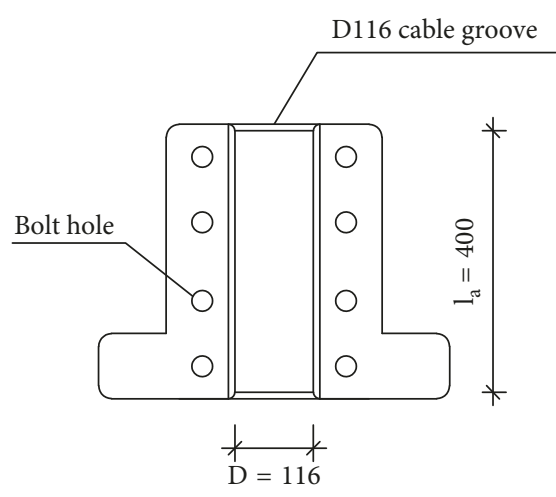

(c)

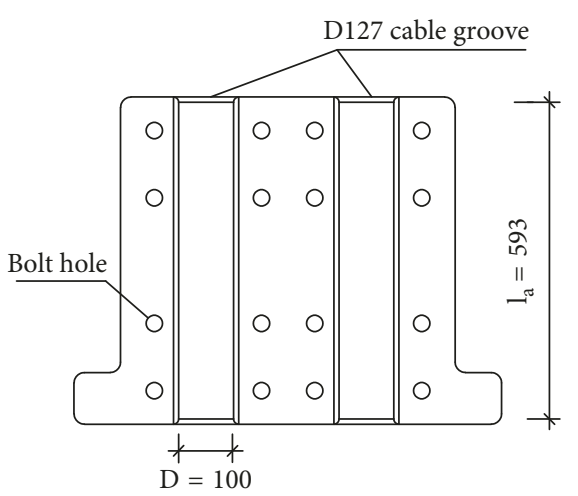

(e)

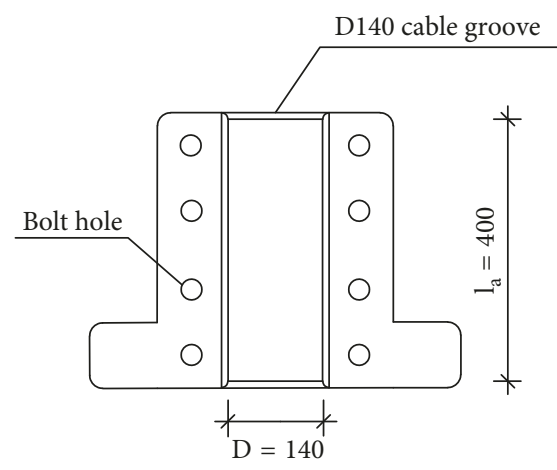

(g)

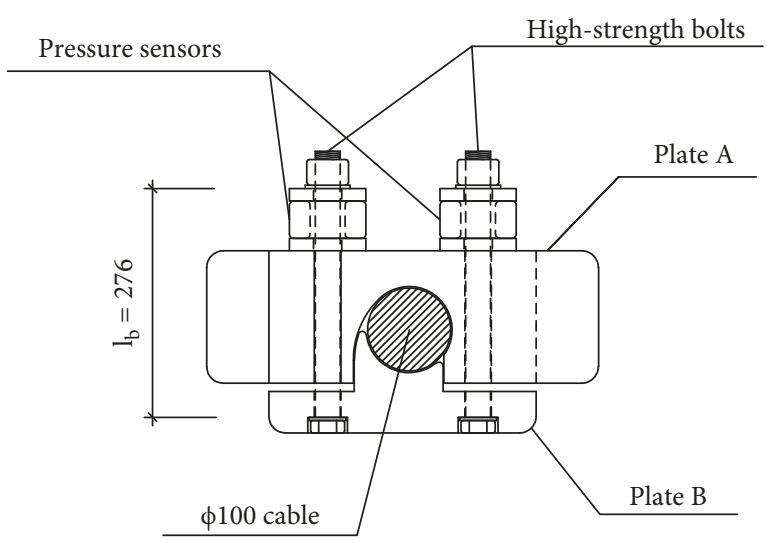

(b)

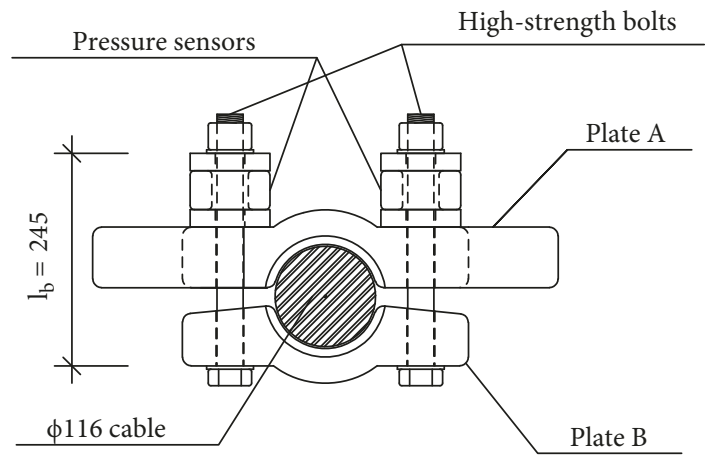

(d)



(f)



(h)

Figure 11: Test specimens of cable clamp. Top view of the (a) $\Phi 100$ cable clamp, (c) D116 cable clamp, (e) $\Phi 127$ cable clamp, and (g) $\Phi 140$ cable clamp. Cross-sectional view of the (b) $\Phi 100$ cable clamp, (d) $\Phi 116$ cable clamp, (f) $\Phi 127$ cable clamp, and (h) $\Phi 140$ cable clamp. 
TABle 2: Number and materials of the specimens.

\begin{tabular}{|c|c|c|c|c|c|c|}
\hline \multicolumn{3}{|c|}{ Cable } & \multicolumn{2}{|c|}{ High-strength bolt } & \multicolumn{2}{|l|}{ Clamp } \\
\hline Diameter & Material & Quantity & Material & Quantity & Material & Quantity \\
\hline$\Phi 100$ & \multirow{4}{*}{$\begin{array}{l}\text { Zinc-5\% aluminum-mixed rare earth alloy coated } \\
\text { tension cable }\end{array}$} & 1 & \multirow{4}{*}{ M27-8.8s } & 4 & \multirow{4}{*}{ G20Mn5QT Casting } & 2 \\
\hline$\Phi 116$ & & 1 & & 8 & & 2 \\
\hline$\Phi 127$ & & 1 & & 8 & & 2 \\
\hline$\Phi 140$ & & 1 & & 8 & & 2 \\
\hline
\end{tabular}

TABLE 3: Specification of specimens.

\begin{tabular}{|c|c|c|c|c|c|c|c|}
\hline Specimen & $\begin{array}{c}\text { Bolt } \\
\text { diameter } \\
d(\mathrm{~mm})\end{array}$ & $\begin{array}{l}\text { Number } \\
\text { of bolts } \\
(m)\end{array}$ & $\begin{array}{c}\text { Net length } \\
\text { of the bolt } \\
l_{\mathrm{b}}(\mathrm{mm})\end{array}$ & $\begin{array}{l}\text { Length of clamp } \\
\text { along the } \\
\text { cable } l_{\mathrm{a}}(\mathrm{mm})\end{array}$ & $\begin{array}{c}\text { Cable } \\
\text { cross-sectional } \\
\text { diameter } D(\mathrm{~mm})\end{array}$ & $\begin{array}{c}\text { Metallic } \\
\text { cross-sectional } \\
\text { area } A_{\mathrm{s}}\left(\mathrm{mm}^{2}\right)\end{array}$ & $\begin{array}{c}\text { Cable } \\
\text { tension force } \\
\Delta F(\mathrm{kN})\end{array}$ \\
\hline $\begin{array}{l}\Phi 100-1 \\
\Phi 100-2\end{array}$ & & 4 & 276 & 417 & 100 & 5894 & 4240 \\
\hline $\begin{array}{l}\Phi 116-1 \\
\Phi 116-2\end{array}$ & & 8 & 245 & 400 & 116 & 7929 & 4277 \\
\hline $\begin{array}{l}\Phi 127-1 \\
\Phi 127-2\end{array}$ & 27 & 8 & 362 & 593 & 127 & 9519 & 6756 \\
\hline $\begin{array}{l}\Phi 140-1 \\
\Phi 140-2\end{array}$ & & 8 & 245 & 400 & 140 & 11467 & 6511 \\
\hline
\end{tabular}

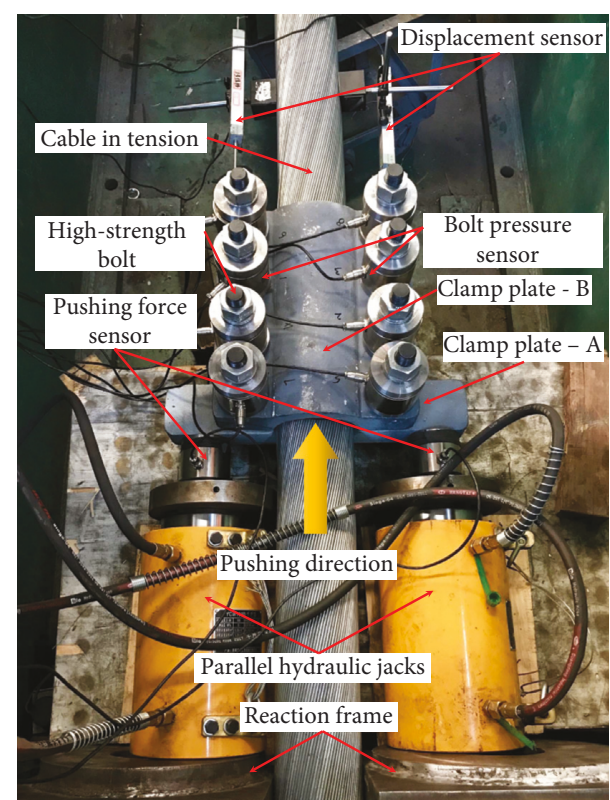

Figure 12: The testing system of the clamp-cable assembly.

the wire was extruded and ground, and the Galfan coating peeled off from the wire; part of the zinc thermal spray coating fell off from the clamp groove, while other debris remained between the twisted wire strands, as shown in Figure 13.

Because the cable clamp groove is treated with a zinc thermal spray coating with a thickness of $1 \mathrm{~mm}$, the zinc coating is much softer than the steel wire, and the wire strand leaves helical indentations on the clamp groove, as shown in Figures 14(c), 14(d), 14(g), and 14(h). The zinc thermal spray coating not only increases the contact area between the wire strand and the clamp groove but also protects the wire body. However, part of the zinc thermal spray coating of the specimens $\Phi 127-1$ and $\Phi 127-2$ peeled from the clamp groove, as shown in Figures 14(a), 14(b), 14(e) and 14(f). This peeling occurs because the sum of the bolt clamping force is high (i.e., approaching $960 \mathrm{kN}$ ), embedding the zinc coating into the wire strand. Therefore, when the clamp plate slides, the zinc coating peels off from the lamp groove.

The theory of adhesive friction proposed by Bowden et al. [23] can explain the sliding process of a cable clamp. In this theory, two polished metallic surfaces in contact touch only at the peaks of their asperities, which may be approximately one micron in height. The peaks are crushed and yield plastically until their total area is sufficient to support the load. The peaks of one surface become welded to those of the other so that when a force, the frictional force, is overcome and sliding occurs, the peaks are sheared off and the surfaces are scraped or "plowed," as shown in Figure 15(a). The peaks on the harder metallic surfaces have a ploughing effect on the softer metallic surfaces. In this case, the frictional force between the two metal surfaces is controlled by two forces: the force required to shear the metallic junctions formed between the surfaces and the ploughing force required to displace the softer metal from the path of the harder metal, as shown in Figure 15(b). The groove of the clamp is coated with a zinc thermal spray, and zinc is much softer than steel wire, so obvious indentations were left on the groove. Thus, the friction force of the cable clamp depends on the ploughing effect.

\subsubsection{Antisliding Friction Force and Friction Coefficient.} During the test, the jack is loaded in steps, the pushing force is recorded, and the slippage data of the two clamp plates are obtained in real time by the automatic data acquisition system. The pushing force-plate slippage curve of each specimen is shown in Figure 16. Three typical stages in the antisliding test process can be determined: 


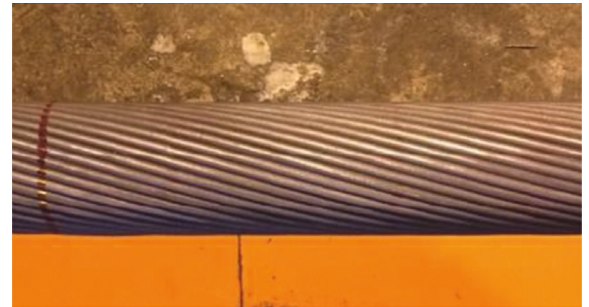

(a)

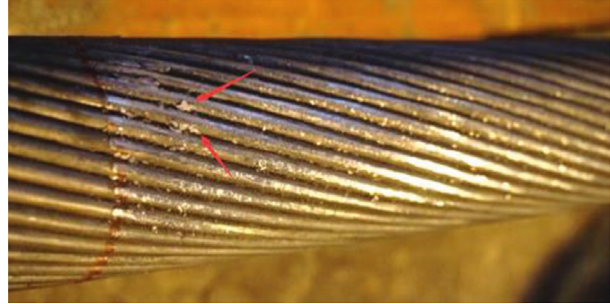

(b)

Figure 13: Clamping surfaces of the Galfan-coated cables before and after the test. (a) Before the test; (b) after the test.



(a)

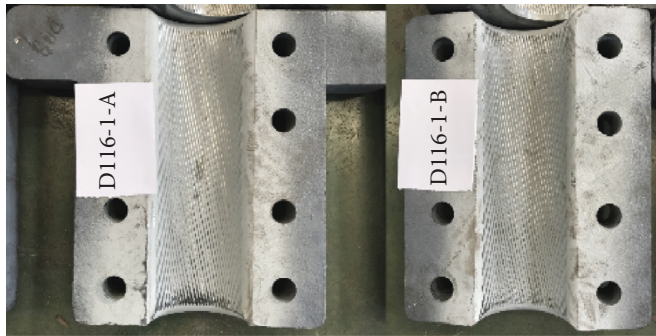

(c)

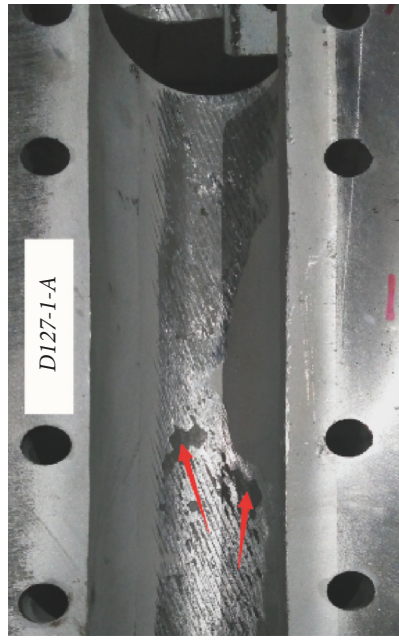

(e)

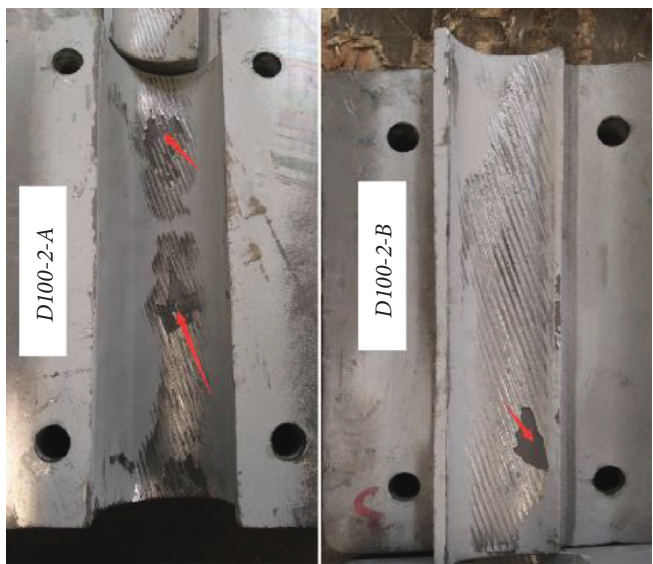

(b)

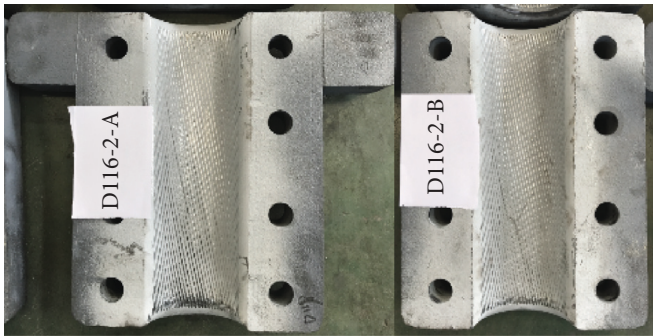

(d)
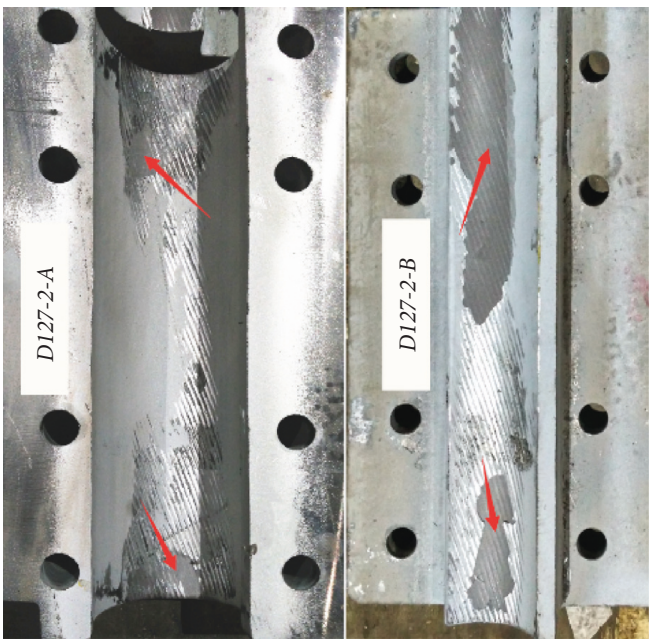

(f)

Figure 14: Continued. 


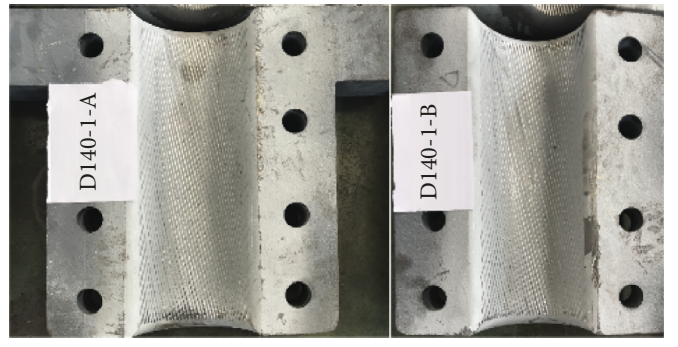

(g)

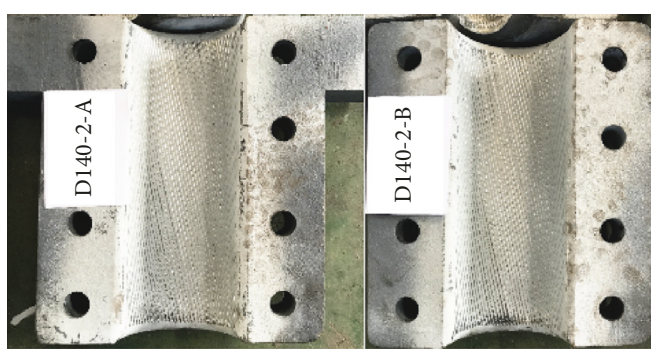

(h)

Figure 14: Clamp grooves after antisliding failure. (a) $\Phi 100-1$; (b) $\Phi 100-2$; (c) $\Phi 116-1$; (d) $\Phi 116-2$; (e) $\Phi 127-1$; (f) $\Phi 127-2$; (g) $\Phi 140-1$; (h) Ф140-2.

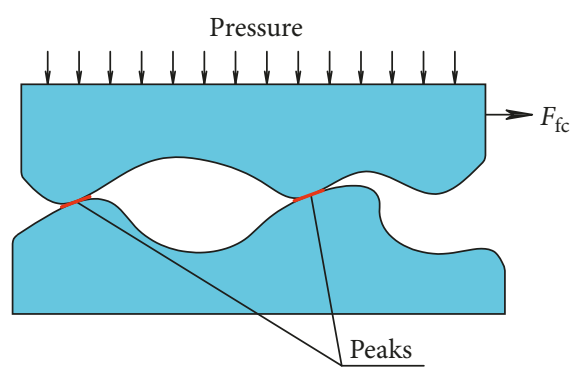

(a)

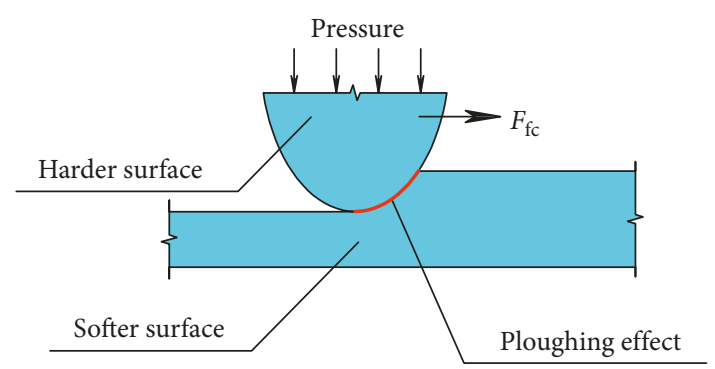

(b)

Figure 15: Adhesion friction and ploughing effect. (a) Adhesive friction; (b) ploughing effect.

(1) Nonslip Stage. During the initial pushing stage, the pushing force increases, but the two plates of the cable clamp do not slip.

(2) Antisliding Stable Stage. The slippage of plate A occurs and increases slowly with the increase in pushing force, and plate B slips slightly as well, while the slippage of both plates are very small, not more than $1 \mathrm{~mm}$.

(3) Antisliding Failure Stage. Finally, the pushing force increases continuously until the friction force of the cable clamp is unable to resist, and the slippage of both plates increases significantly. The phenomenon of sliding friction is observed for both plates, and antisliding failure is declared.

The maximum pushing force during the antisliding stable stage is determined as the ultimate antisliding friction force of the cable clamp. After experiencing long-term creep and cable tension, the clamping force of the high-strength bolts becomes stable, and the remaining clamping force of the bolts is defined as the effective bolt clamping force. The cable clamp consists of two plates. When antisliding failure occurs, the two clamp plates work together and both provide friction force. Therefore, when calculating the friction coefficient, both friction surfaces should be considered, as in equation (16); the result of (16) is defined as the comprehensive friction coefficient. The results of the ultimate antisliding friction force, the effective bolt clamping force, and the comprehensive friction coefficient are listed in Table 4 for each specimen. The comprehensive friction coefficient ranges from 0.30 to 0.46 , and the ultimate antisliding friction force is positively correlated with the effective bolt clamping force:

$$
\bar{\mu}=\frac{1}{2} \cdot \frac{F_{\mathrm{fc}}}{P_{e, \mathrm{tot}}},
$$

where $\bar{\mu}$ is the comprehensive friction coefficient, $F_{\mathrm{fc}}$ is the ultimate antisliding friction force of the cable clamp, and $P_{e, \text { tot }}$ is the sum of the effective bolt clamping forces.

3.3.3. Stress Relaxation of High-Strength Bolts. Stress relaxation [24] refers to the phenomenon that as the total deformation (elastic deformation and plastic deformation) of a member remains unchanged, the plastic deformation increases with creep and the elastic deformation decreases correspondingly, causing the stress to slowly decrease and ultimately stabilize. The change in the bolt clamping force was recorded by pressure sensors throughout the test, and the curve of the bolt clamping force vs. time is shown in Figure 17. The creep curve is similar to the natural logarithm curve. The reduction in bolt clamping force decays rapidly in the initial stage of the first two hours, slowly decays in next two hours, and gradually stabilizes after 20 hours. After the decay time exceeds 18 hours, the attenuation curve approaches a horizontal line. When the average percentage of the reduction in the bolt clamping force per hour is less than $1 \%$, that is, the change per hour is less than $0.2 \mathrm{kN}$, the influence of these changes can be ignored, and the attenuation is considered stable. After tensioning the cables, the bolt clamping force decreases sharply and then stabilizes at a constant value.

Cable tension leads to the shrinkage of the cable body, which in turn reduces the preload of the high-strength bolts. The average values of the bolt clamping forces for each stage 
are listed in Table 5. The results show that from the initial stage to the creep stable stage, the average percentages of the bolt clamping force relaxation range from $25.4 \%$ to $29.8 \%$; from the creep stable stage to the cable tension stage, the average percentages of the bolt clamping force relaxation range from $47.0 \%$ to $51.5 \%$. In each test, the cable tensioning is divided into 10 stages. The curves of the bolt tightening force applied to the high-strength bolts during the tensioning of the cables are shown in Figure 18. As the figure illustrates, during the process of graded tensioning of the cables, an obvious loss of bolt clamping force occurs and the force decreases linearly with the increase in the tension grade. However, the reduction among the individual bolts varies. The two main reasons for this result are as follows: (1) the bolts are not tightened at the same time, and relaxation occurs in the bolts that are tightened first and (2) a few bolts may be in contact with the walls of the bolt holes in the tightening process, thus affecting the relaxation of the bolt clamping force.

3.4. Comparison of Theoretical Model and Laboratory Tests. The specifications of the specimens, mechanical properties of the materials, and comparison results of the theoretical model and the laboratory tests are listed in Tables 2, 3, and 6 , respectively. In the theoretical model, the elastic modulus of the cable is reduced to maintain the same equivalent stiffness of the cable section before and after the variation in the cable section areas, and the chamfers at both ends are omitted when calculating the length of the clamp groove. The results show that all the actual attenuation values of the clamping force of a single tested bolt are smaller than the theoretical values. The errors of specimens $\Phi 116$ and $\Phi 140$ range from $18.0 \%$ to $20.1 \%$, but the errors of specimens $\Phi 100$ and $\Phi 127$ range from $0.6 \%$ to $6.2 \%$; these error ranges are quite different.

The stiffness of a rigid body is considered in the theoretical model; in other words, when the clamp is applied with the bolt clamping force, the clamp will not deform. However, in practice, slight deformation inevitably occurs after the load is applied. As shown in Figure 19, during the beginning of the test, the initial net length of the bolt is $a$. Then, the high-strength bolts undergo the initial preload, the cable does not undergo applied stress, the clamp plate deforms, and the net length of the bolt is defined as $b$. After the bolt clamping force stabilizes and the cable is tensioned to the design load, the cable diameter clearly decreases and the net length of the bolt is defined as $c$. Meanwhile, the bolt clamping force is also reduced, so the deformation of the clamp plate will rebound, and the net length of the bolt is $d$. This change will lead to the phenomenon that the actual attenuation of the bolt clamping force is lower than the corresponding theoretical value. Therefore, if the stiffness of the cable clamp is lower, the rebound will be larger and the net length of the bolt will be $d$ ', as shown in Figure 19. In this case, the attenuation of the bolt clamping force is much lower than the theoretical value. For clamps with greater stiffness, the rebound deformation is smaller and vice versa. Therefore, when the cable is tensioned, the clamp with a relatively higher stiffness will lose more clamping force than the clamp with a lower stiffness. In this test, because the stiffnesses of the $\Phi 100$ and $\Phi 127$ clamp plates were clearly higher than those of $\Phi 116$ and $\Phi 140$, the attenuations of the bolt clamping forces of $\Phi 100$ and $\Phi 127$ reduced more and were close to the theoretical values.

In practical engineering applications, the installation of high-strength bolts in cable clamps is usually carried out on the ground for convenience. However, after the structure is completed, the clamps are in the air at a high altitude, so it is difficult to tighten the bolts. Therefore, when designing a cable clamp, the stiffness of the clamp plate should be minimized to reduce the decrease in the bolt clamping force to ensure the bearing capacity.

\section{Conclusion}

When following Eurocode 3, it is necessary to consider the effect of cable tension and long-term creep to determine the ultimate antisliding force of the cable clamp. Therefore, a theoretical model based on the theory of transversely isotropic material and the generalized Hook's Law was developed to predict the attenuation of the bolt clamping force of a clamp by considering cable tension. To explore the mechanism of the antisliding performance of cable clamps and verify the theoretical model, an innovative laboratory test was designed and carried out. The following conclusions were drawn:

(1) Through the laboratory test, it was determined that long-term creep and cable tension will cause the bolt to attenuate. Both of these factors must be fully considered in the design and testing of cable clamps. The long-term creep curve is similar to the natural logarithmic curve. The attenuation curve with cable tension is approximately a straight line. For a highstrength bolt after installation, it will take approximately 20 hours on average to stabilize. After the creep stabilizes and cable tensioning is performed, the bolt clamping force only slightly changes. The final attenuation of the bolt clamping force is approximately $51 \%$.

(2) The antisliding test process for the cable clamp was described by identifying three main typical stages: (1) nonslip stage, (2) antisliding stable stage, and (3) antisliding failure stage. The two plates work together to provide the antisliding force. The comprehensive friction coefficient of the clamp varies from 0.30 to 0.46 . Because the antisliding performance of the clamp depends on the ploughing effect, the contact of the surfaces of the clamp groove and the cable body should be sufficient. The machining precision of casting steel, especially the arc surface of the clamp groove, should be guaranteed.

(3) The theoretical model can predict the attenuation of the bolt clamping force caused by cable tension. The cable tension force $\Delta F$, cable diameter $D$, bolt 




- Plate A

Plate B

(a)

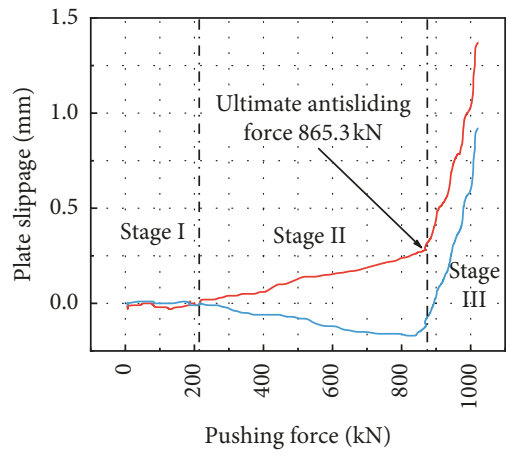

Plate A

Plate B

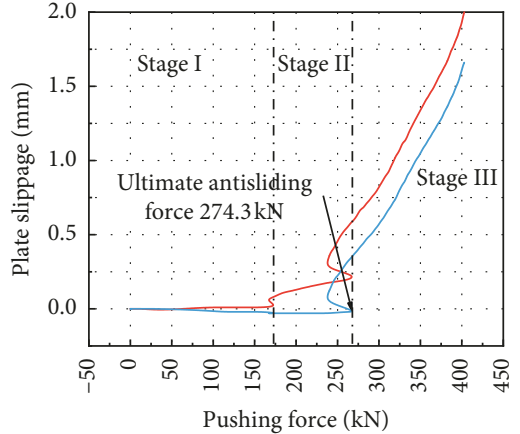

— Plate A

Plate B

(b)

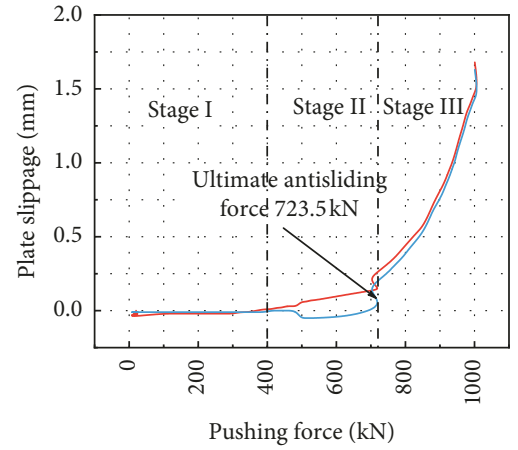

- Plate A

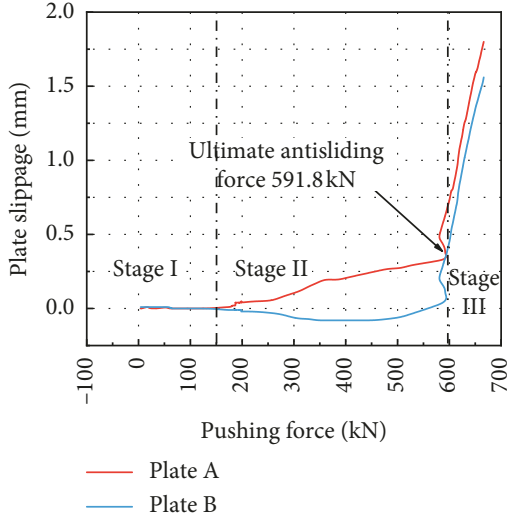

(c)

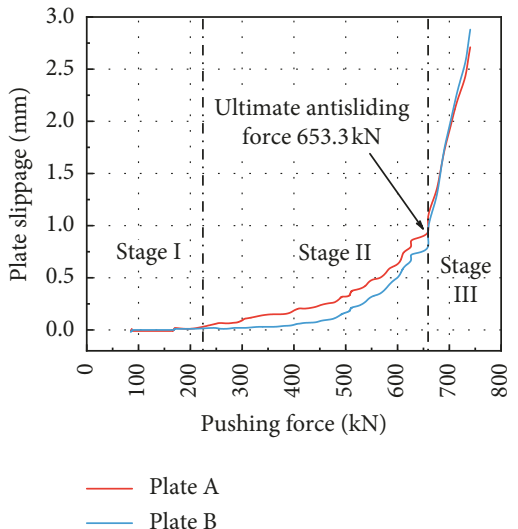

(f)

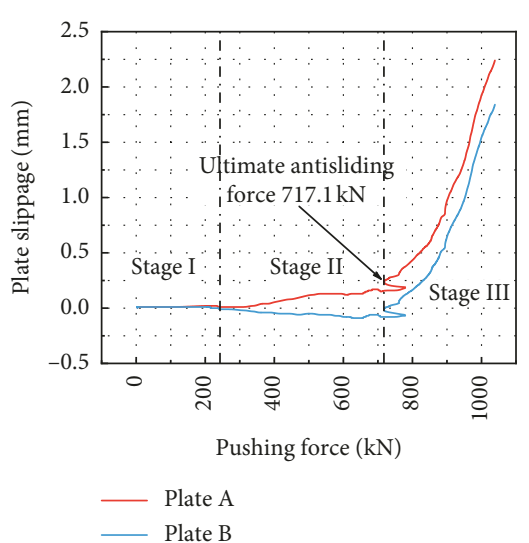

(g) (e)

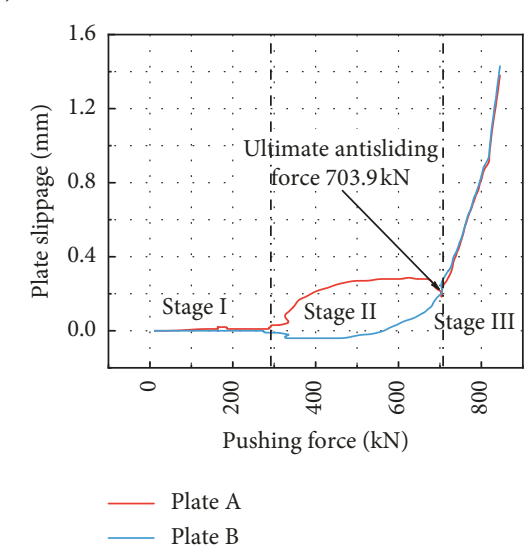

(h)

FIGURE 16: Pushing force vs. plate slippage curve. (a) Ф100-1; (b) Ф100-2; (c) Ф116-1; (d) Ф116-2; (e) Ф127-1; (f) $\Phi 127-2$; (g) $\Phi 140-1$; (h) Ф140-2.

TABLE 4: Ultimate antisliding force and comprehensive friction coefficient.

\begin{tabular}{lcccc}
\hline Specimen & $\begin{array}{c}\text { Cable tension } \\
\text { force }(\mathrm{kN})\end{array}$ & $\begin{array}{c}\text { Sum of effective bolt } \\
\text { clamping force }(\mathrm{kN})\end{array}$ & $\begin{array}{c}\text { Ultimate antisliding } \\
\text { force }(\mathrm{kN})\end{array}$ & $\begin{array}{c}\text { Comprehensive } \\
\text { friction coefficient }\end{array}$ \\
\hline$\Phi 100-1$ & \multirow{2}{*}{4240} & 404.1 & 282.9 & 0.35 \\
$\Phi 100-2$ & & 410.4 & 274.3 & 0.33 \\
\hline$\Phi 116-1$ & \multirow{2}{*}{4277} & 978.6 & 591.8 & 0.30 \\
$\Phi 116-2$ & \multirow{2}{*}{6756} & 934.4 & 723.5 & 0.46 \\
\hline $127-1$ & \multirow{2}{*}{6511} & 980.7 & 653.3 & 0.37 \\
$\Phi 127-2$ & & 969.0 & 717.1 & 0.34 \\
$\Phi 140-1$ & & 883.8 & 703.9 & 0.41 \\
\hline $140-2$ & & 892.2 & 0.39 \\
\hline
\end{tabular}



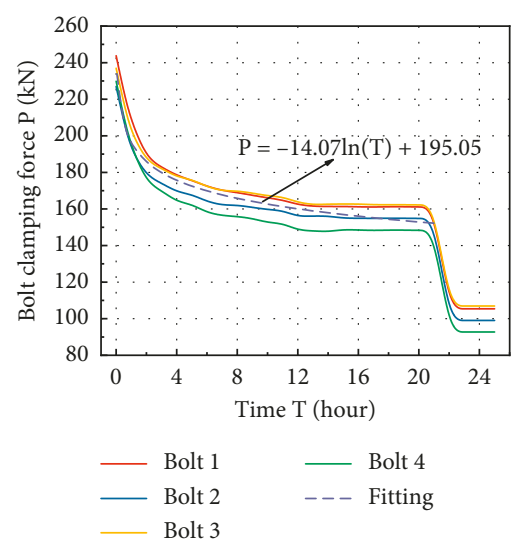

(a)

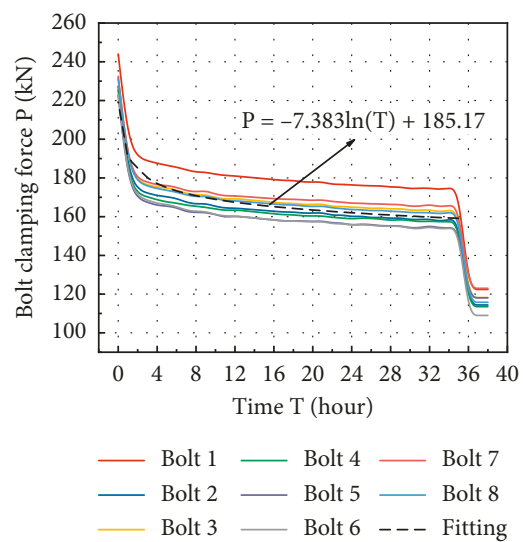

(d)

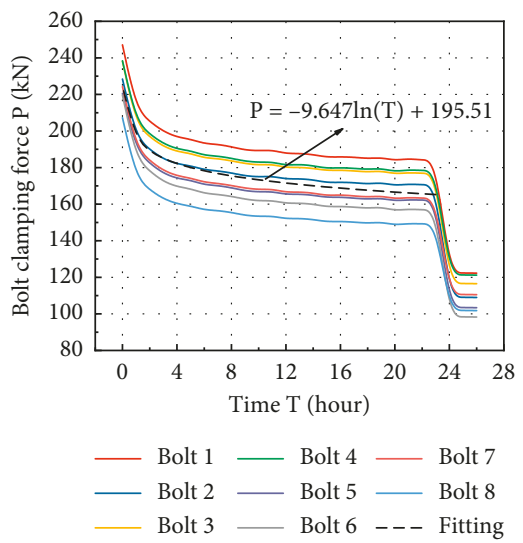

(g)
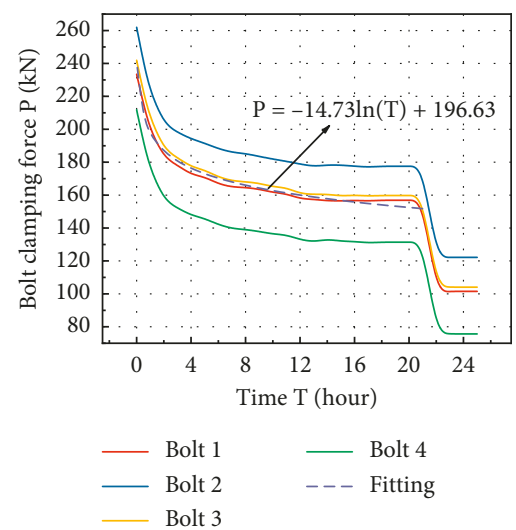

(b)

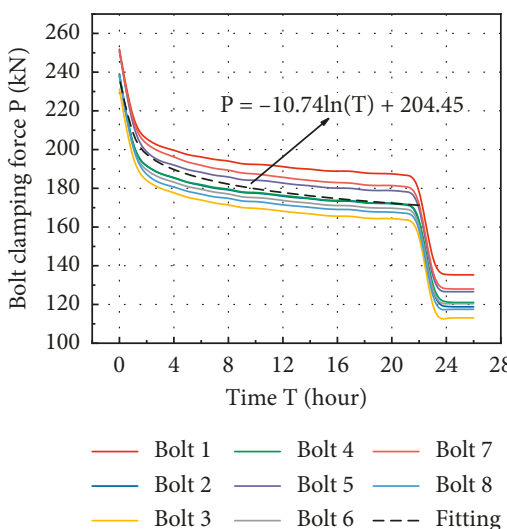

(e)

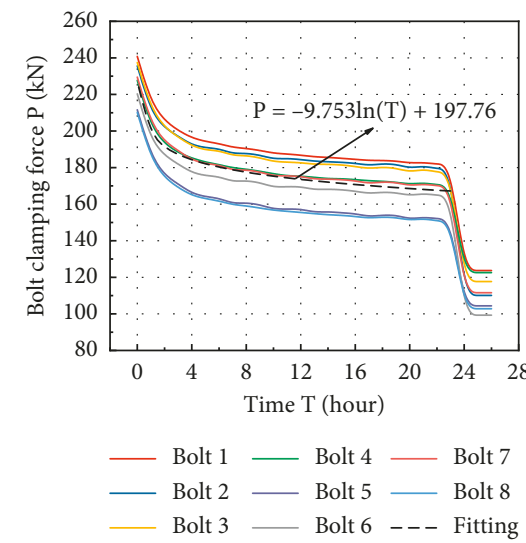

(h)


(c)



(f)

FiguRE 17: Bolt clamping force creep curves vs. time. (a) $\Phi 100-1$; (b) $\Phi 100-2$; (c) $\Phi 116-1$; (d) $\Phi 116-2$; (e) $\Phi 127-1$; (f) $\Phi 127-2$; (g) $\Phi 140-1$; (h) $\Phi 140-2$.

TABle 5: Average bolt clamping force at different stages.

\begin{tabular}{|c|c|c|c|c|c|c|}
\hline \multirow{2}{*}{ Specimen } & \multicolumn{3}{|c|}{ Average bolt clamping force $(\mathrm{kN})$} & \multicolumn{3}{|c|}{ Reduction percentage of bolt clamping force } \\
\hline & Initial stage & Creep stable stage & Cable tension stage & Initial stage & Creep stable stage & Cable tension stage \\
\hline$\Phi 100-1$ & 234.4 & 156.6 & 101.0 & - & $33.2 \%$ & $56.9 \%$ \\
\hline$\Phi 100-2$ & 237.3 & 158.4 & 102.6 & - & $33.3 \%$ & $56.8 \%$ \\
\hline$\Phi 116-1$ & 230.8 & 166.8 & 122.3 & - & $27.7 \%$ & $47.0 \%$ \\
\hline$\Phi 116-2$ & 229.7 & 161.1 & 116.8 & - & $29.8 \%$ & $49.1 \%$ \\
\hline$\Phi 127-1$ & 242.4 & 173.0 & 122.6 & - & $28.6 \%$ & $49.4 \%$ \\
\hline$\Phi 127-2$ & 230.7 & 172.2 & 121.1 & - & $25.4 \%$ & $47.5 \%$ \\
\hline$\Phi 140-1$ & 228.0 & 167.7 & 110.5 & - & $26.4 \%$ & $51.5 \%$ \\
\hline$\Phi 140-2$ & 226.7 & 168.0 & 111.5 & - & $25.9 \%$ & $50.8 \%$ \\
\hline
\end{tabular}



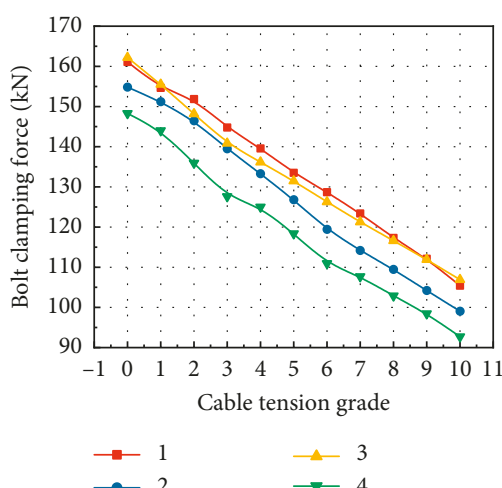

(a)
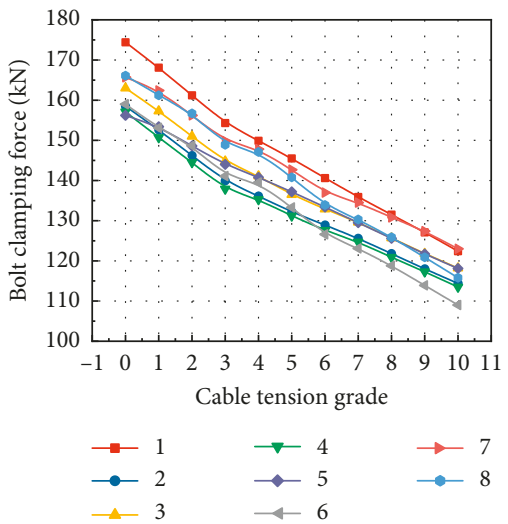

(d)
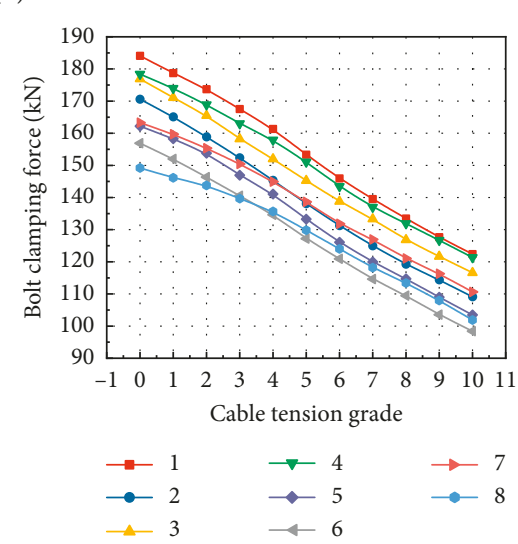

(g)
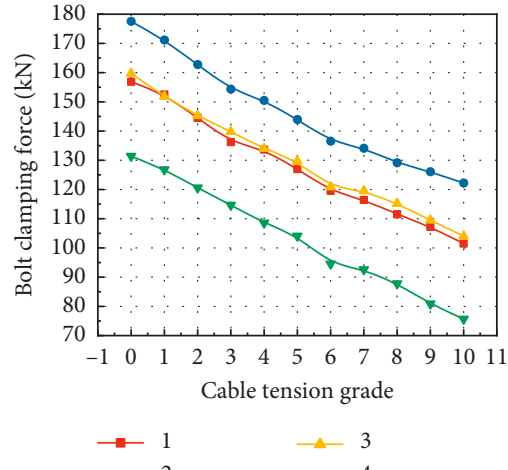

(b)
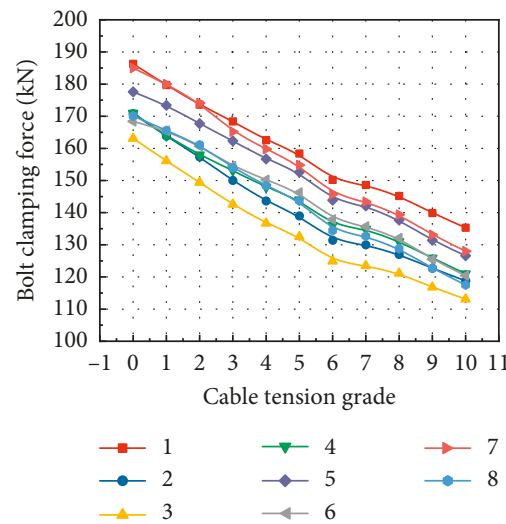

(e)
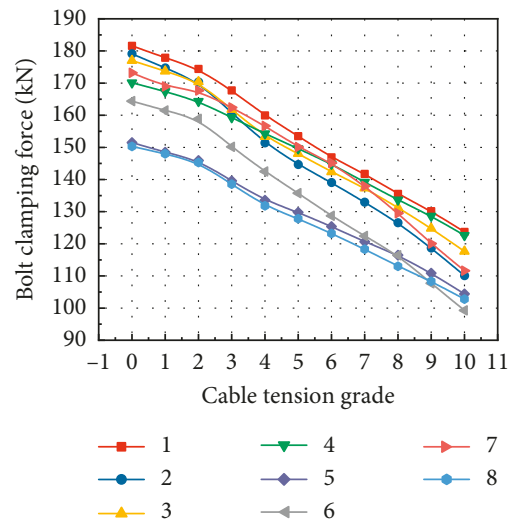

(h)
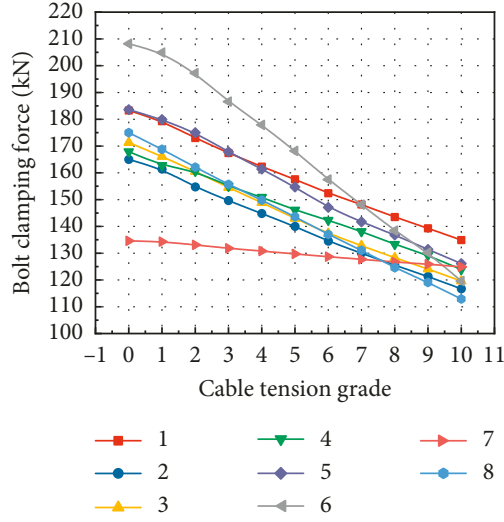

(c)
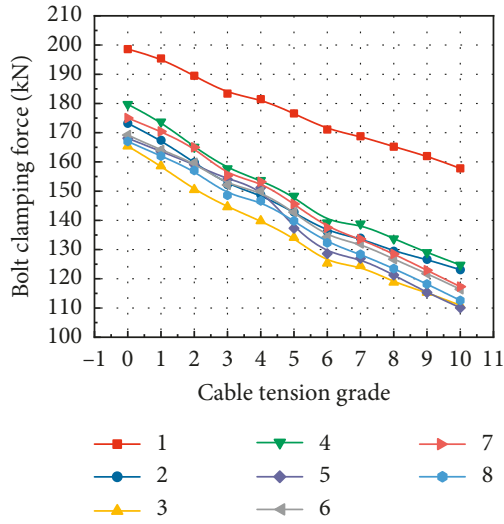

(f)

FIGURE 18: Reduction in bolt clamping force during cable tensioning. (a) $\Phi 100-1$; (b) $\Phi 100-2$; (c) $\Phi 116-1$; (d) $\Phi 116-2$; (e) $\Phi 127-1$; (f) $\Phi 127-$ 2; (g) Ф140-1; (h) Ф140-2.

TABLE 6: Comparison of theoretical and actual values of the reduction in bolt clamping force with cable tension.

\begin{tabular}{|c|c|c|c|c|c|c|c|c|c|}
\hline \multirow{2}{*}{ Specimen } & \multicolumn{2}{|c|}{ Poisson's ratio of cables } & \multirow{2}{*}{$\begin{array}{l}\text { Reduction } \\
\text { factor of } \\
\text { elastic } \\
\text { modulus } \varphi_{e}\end{array}$} & \multicolumn{3}{|c|}{ Equivalent elastic modulus (MPa) } & \multicolumn{3}{|c|}{$\begin{array}{l}\text { Attenuation value of single bolt } \\
\text { clamping force } P_{\text {tot }}(\mathrm{kN})\end{array}$} \\
\hline & $\begin{array}{c}\text { Axial } \\
v_{r z}\end{array}$ & $\begin{array}{c}\text { Circumferential } \\
v_{r \theta}\end{array}$ & & $\begin{array}{c}\text { Axial } \\
E_{z z} \times 10^{5}\end{array}$ & $\begin{array}{c}\text { Radial } \\
E_{r r} \times 10^{5}\end{array}$ & $\begin{array}{l}\text { Circumferential } \\
E_{\theta \theta} \times 10^{5}\end{array}$ & Theoretical & $\begin{array}{l}\text { Average } \\
\text { actual }\end{array}$ & Error \\
\hline$\Phi 100-1$ & \multirow{8}{*}{0.3} & \multirow{8}{*}{0} & \multirow{2}{*}{0.75} & \multirow{2}{*}{1.20} & \multirow{2}{*}{1.55} & \multirow{2}{*}{1.55} & \multirow{2}{*}{56.16} & 55.6 & $1.0 \%$ \\
\hline$\Phi 100-2$ & & & & & & & & 55.8 & $0.6 \%$ \\
\hline$\Phi 116-1$ & & & \multirow{2}{*}{0.75} & \multirow{2}{*}{1.20} & \multirow{2}{*}{1.55} & \multirow{2}{*}{1.55} & \multirow{2}{*}{53.2} & 44.5 & $19.6 \%$ \\
\hline$\Phi 116-2$ & & & & & & & & 44.3 & $20.1 \%$ \\
\hline$\Phi 127-1$ & & & \multirow{2}{*}{0.75} & \multirow{2}{*}{1.20} & \multirow{2}{*}{1.55} & \multirow{2}{*}{1.55} & \multirow{2}{*}{53.5} & 50.4 & $6.2 \%$ \\
\hline$\Phi 127-2$ & & & & & & & & 51.0 & $4.9 \%$ \\
\hline$\Phi 140-1$ & & & \multirow{2}{*}{0.74} & \multirow{2}{*}{1.19} & \multirow{2}{*}{1.53} & \multirow{2}{*}{1.53} & \multirow{2}{*}{67.5} & 57.2 & $18.0 \%$ \\
\hline$\Phi 140-2$ & & & & & & & & 56.4 & $19.7 \%$ \\
\hline
\end{tabular}






Figure 19: Deformation and rebound of a clamp plate.

net length $l_{\mathrm{b}}$, and the total cross-sectional area of all the bolts $A_{\text {sum,b }}$ are the key parameters significantly affecting the variation in bolt clamping force, which should be considered carefully when designing cable clamps. When the clamp stiffness is high, the theoretical attenuation calculated by the formula is close to the actual value. When the clamp stiffness is low, the actual attenuation will be approximately $19.3 \%$ less than the theoretical value. Therefore, when designing the cable clamp, the thickness of the cover plate should be minimized to avoid using a steel plate with an excessive stiffness.

In summary, with the proposed theoretical model and new laboratory testing approach, acceptable results have been obtained, which are helpful in the design and testing of cable clamps. Based on the test method proposed, more clamp types will be designed for research. Cable clamp optimization will be carried out to improve their antisliding performance.

\section{Data Availability}

The data used to support the findings of this study are available from the author upon request.

\section{Conflicts of Interest}

The authors declare that they have no conflicts of interest.

\section{Acknowledgments}

This study was supported by the National Natural Science Foundation of China (Grant no. 6505000147) and the Jiangsu Postgraduate Practical Innovation Plan (Grant no. SJCX18_0028).

\section{References}

[1] D. Wang, F. Zhang, C. Gao, Z. Jian, and H. Chen, "Research and design of steel structure of Shanghai Pudong
International Airport terminal (first Phase of the project)," Journal of Building Structures, vol. 20, 1999.

[2] E. D. S. Caetano, R. Bartek, F. Magalhães, C. Keenan, and G. Trippick, "Assessment of cable forces at the London 2012 Olympic stadium roof," Structural Engineering International, vol. 23, no. 4, pp. 489-500, 2013.

[3] B. Luo, M. Ding, G. Xie, and Z. Guo, "Accumulative traction construction analysis of the FAST cable-net structure," KSCE Journal of Civil Engineering, vol. 22, no. 10, pp. 3707-3717, 2018.

[4] M. Seidel, Tensile Surface Structures: A Practical Guide to Cable and Membrane Construction, John Wiley \& Sons, Hoboken, NJ, USA, 2009.

[5] W. J. Lewis, Tension Structures: Form and Behaviour, Thomas Telford, London, UK, 2003.

[6] H. Liu and Z. Chen, "Structural behavior of the suspen-dome structures and the cable dome structures with sliding cable joints," Structural Engineering and Mechanics, vol. 43, no. 1, pp. 53-70, 2012.

[7] G. Luo, "Cable clamp slipping analysis and treatments," Transportation Science \& Technology, no. 3, 2016.

[8] European Committee for Standardization, Eurocode 3: Design of Steel Structures, Part 1.11: Design of Structures with Tension Components EN 1993-1-11, European Committee for Standardization, Brussels, Belgium, 2006.

[9] American Society of Civil Engineers, "Structural applications of steel cables for buildings," in ASCE 19-96, American Society of Civil Engineers, New York, NY, USA, 2016.

[10] Ministry of Transport of the People's Republic of China, Specifications for Design of Highway Suspension Bridge JTG/T D65-05-2015, Ministry of Transport of the People's Republic of China, Beijing, China, 2015.

[11] C. Zhao, M. Yan, A. Zhang, Y. Wei, and F. Wang, "Experimental study of slip resistance of cable clamps of Hongdu bridge," World Bridges, vol. 1, p. 15, 2013.

[12] Z.-B. Zhou, Q.-H. Yuan, C.-D. Zhou, and S.-L. Shu, "Study of antisliding tests for cable clamps of suspension bridge main cables made up of zinc-aluminum alloy coated steel wires," World Bridge, vol. 5, pp. 40-43, 2015.

[13] B. Luo, Z. X. Guo, and F. Gao, "Research on non-brackettowlifting construction technology and complete process analysis of cable dome," Journal of Building Structures, vol. 5, 2012.

[14] D. Castro-Fresno, J. J. del Coz Díaz, M. Alonso Martínez, E. Blanco-Fernandez, and J. A. Polanco Madrazo, "Numerical and experimental study of a new type of clip for joining cables," Engineering Structures, vol. 44, pp. 107-121, 2012.

[15] P. Zhuge, Z. Zhang, S. Wang, Y. Ding, S. Qiang, and S. O. Architectural, "Anti-slip performance of interface between carbon fiber-reinforced plastic main cable and cable clamp for large-span suspension bridges," Journal of Southwest Jiaotong University, vol. 49, pp. 208-239, 2014.

[16] Y. Chen and J. Feng, Numerical Simulations on the Cable Clamp of a Concave Cable Arch, Trans Tech Publications, Switzerland, 2012.

[17] H. Ding, W. Chen, and L. Zhang, Elasticity of Transversely Isotropic Materials, Vol. 126, Springer Science \& Business Media, Berlin, Germany, 2006.

[18] F. Dell'Isola, G. Sciarra, and S. Vidoli, "Generalized Hooke's law for isotropic second gradient materials," The Royal Society, vol. 465, no. 2107, pp. 2177-2196, 2009.

[19] H. Kai, "Study on the stress of main cable under the railway suspension bridge long cable clamp and the sliding resistance bearing capacity of cable clamp," Master Degree, Southeast Jiaotong University, Chengdu, China, 2017. 
[20] Standardization Administration of the P.R.C., Zinc-5\% Aluminum-Mixed Mischmetal Alloy-Coated Steel Wire and Steel Wire Strand GB/T. 20492-2006, Standardization Administration of the P.R.C., Beijing, China, 2006.

[21] MOHURD, "Technical specification for cast steel structure," in JGJ/T 395-2017: Ministry of Housing and Urban-Rural Development of the People's Republic of China, MOHURD, Beijing, China, 2017.

[22] Standardization Administration of the P.R.C., Specifications of High Strength Bolts with Large Hexagon Head, Large Hexagon Nuts, Plain Washers for Steel Structures GB/T 1231-2006, Standardization Administration of the P.R.C., Beijing, China, 2006.

[23] F. P. Bowden, F. P. Bowden, and D. Tabor, The Friction and Lubrication of Solids, Vol. 1, Oxford University Press, Oxford, UK, 2001.

[24] J. Guo, F. Xuan, and L. He, "Stress relaxation performance and prediction models for bolt material of $1 \mathrm{Cr} 10 \mathrm{Ni}$ MoW2VNbN," Nuclear Power Engineering, vol. 29, pp. 119124,2008 . 


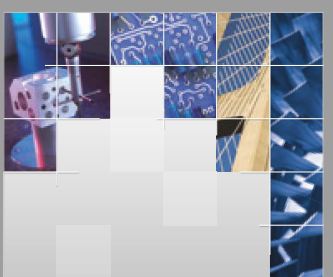

\section{Enfincering}
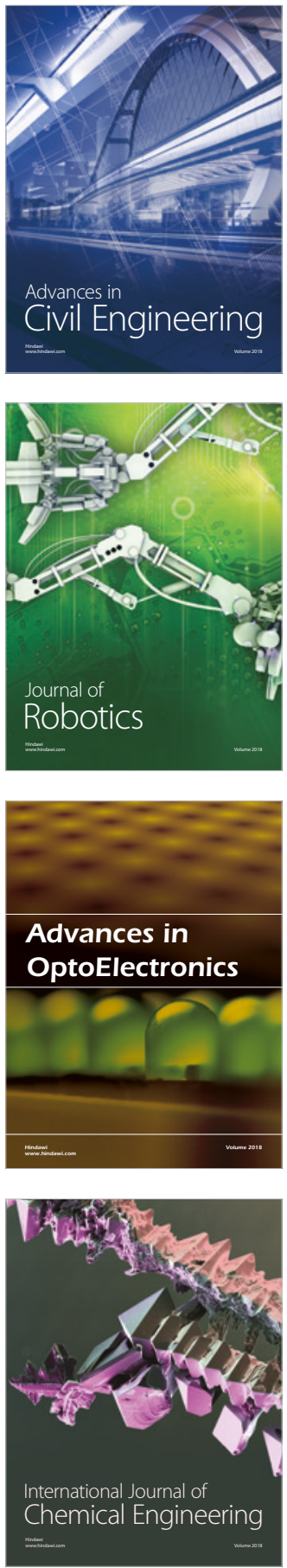



\section{Rotating \\ Machinery}

The Scientific World Journal

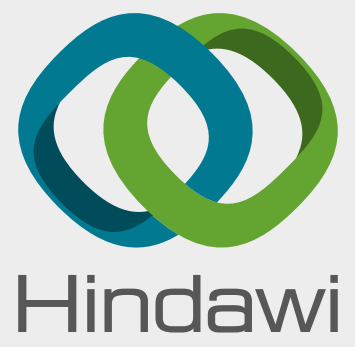

Submit your manuscripts at

www.hindawi.com

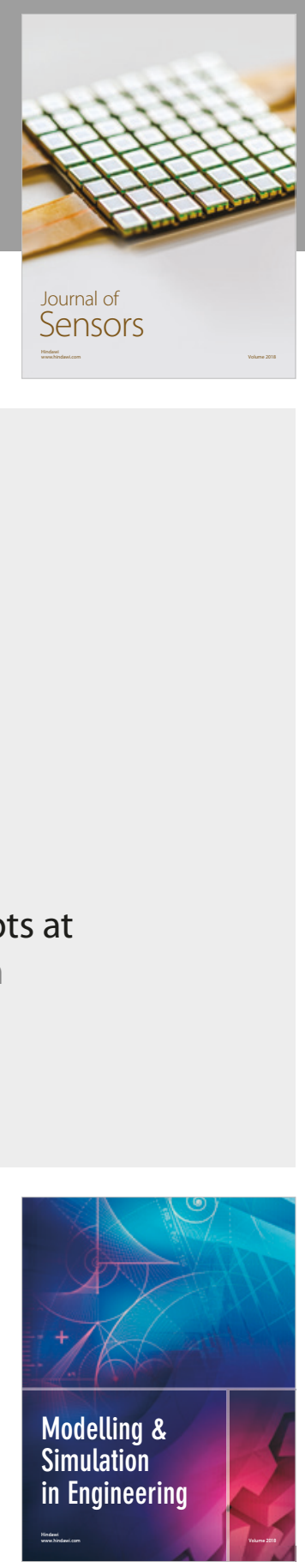

\section{Advances \\ Multimedia}
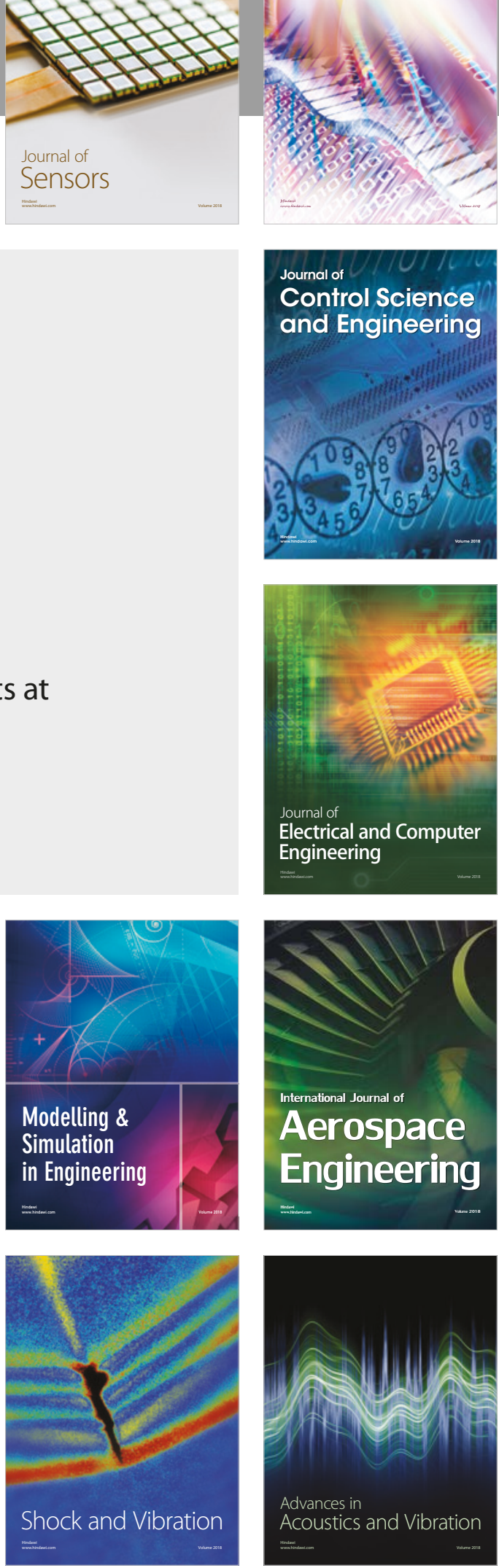